\title{
ANTIMICROBIAL AND ANTIOXIDANT ACTIVITIES OF SELECTED PLANTS USED BY POPULATIONS FROM JURUENA VALLEY, LEGAL AMAZON, BRAZIL
}

\author{
LARISSA IRENE DA SILVAa, ARUNACHALAM KARUPPUSAMYa, FABIO MIYAJIMA ${ }^{\text {bc }}$, IVANA MARIA POVOA

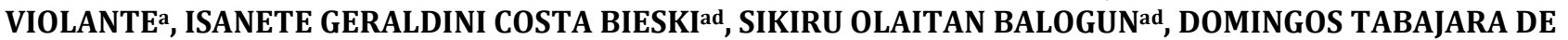 \\ OLIVEIRA MARTINS ${ }^{\mathrm{a}^{*}}$
}

\begin{abstract}
aArea of Pharmacology, Department of Basic Health in Sciences, Faculty of Medicine, Federal University of Mato Grosso, Cuiabá, Mato Grosso, Brazil, bDepartment of Pharmacology, Translational Medicine Institute, University of Liverpool, United Kingdom, 'Department of Physiology and Pharmacology, Federal University of Ceara, Brazil, dCurso de Farmácia, Faculdade de Noroeste de Mato Grosso, Associação Juinense de Ensino Superior (AJES), Juína, Mato Grosso, Brazil

Email: taba@terra.com.br

Received: 14 Jan 2017 Revised and Accepted: 31 Mar 2017
\end{abstract}

\begin{abstract}
Objective: The purpose of this study was to evaluate selected Brazilian plants from Juruena valley region of Mato Grosso, for their in vitro antimicrobial and antioxidant activities.

Methods: The powder obtained from different parts of the twenty-six (26) plants were macerated in hydroethanolic solution to obtain the extracts. The hydroethanolic extracts were tested for their in vitro antimicrobial activity by determining the MIC using broth microdilution. The 2, 2diphenyl-1-picrylhydrazyl (DPPH) radical, ferric reducing antioxidant power (FRAP) and nitric oxide (NO) methods were used for the determination of antioxidant activities. Correlation between classes of secondary metabolites and antioxidant activity was assessed.

Results: Phanera glabra extract (HEPg) showed broad antibacterial spectrum, presenting the best activity against Klebsiella pneumoniae. Hevea microphylla extract (HEHm) presented a narrow spectrum of antibacterial activity with strong effect against Shigella flexneri. The only plant with broad spectrum antifungal activity was Bertholletia excelsa (HEBe), with moderate activity against strains of Aspergillus and Candida. The following extracts were prominent regarding their activities in the DPPH and FRAP assays-HEBe, Cariniana rubra (HECr) and in the FRAP assay alone, Cedrela odorata (HECo) and HEPg. None of the extracts was active in the NO assay. A significant association was observed between DPPH activity and the total phenolic contents.
\end{abstract}

Conclusion: Our results justified the use of some of the investigated plants in the Brazilian ethnomedicine. The antibacterial activities of these plants are bacteriostatic in nature. These findings support that a number of investigated plants could be a valuable source of new antioxidant and antimicrobial compounds that can potentially deliver novel mechanisms of actions. However, further studies are required.

Keywords: Medicinal plants, Antifungal, Antibacterial, Phytochemical analysis

(C) 2017 The Authors. Published by Innovare Academic Sciences Pvt Ltd. This is an open access article under the CC BY license (http://creativecommons.org/licenses/by/4.0/) DOI: http://dx.doi.org/10.22159/ijpps.2017v9i5.17086

\section{INTRODUCTION}

The usefulness of medicinal plants in the management, cure, and prevention of diseases, as described by local people since time immemorial, have aroused both commercial and scientific interests [1]. Several epidemiological studies have endorsed the importance of high consumption of secondary plant products found in fruits and vegetables, for the modulation of degenerative diseases. Brazil possess the largest floristic diversity on Earth, as it contains six continental biomes; the Amazon rainforest, the Brazilian Cerrado, the Caatinga, the Atlantic forest, the Pantanal, and the Pampas. The Amazon rainforest being the most noteworthy, since it is the largest tropical forest in the world, and whose diversity of plant species constitutes an endless source for the research of phytotherapies and new molecules with biological activities [2].

The state of Mato Grosso (MT), the largest agricultural producer in Brazil, contains three important biogeographical regions (Amazon rainforest, Cerrado (Brazilian savannah) and Pantanal) and a rich ethnocultural diversity, represented by 42 indigenous groups (42,538 individuals) and traditional quilombola, cabocla and riverine communities Amazon rainforest, Cerrado (Brazilian savannah) and Pantanal [3].

The region of Juruena valley which encompasses seven important cities, namely Juína, Castanheira, Brasnorte, Juruena, Aripuanã, Cotriguaçu and Colniza, is situated in the northern part of Mato Grosso, within the officially recognized Legal Amazon region. The region inhabitants, as at the time of the study, were 139,524 , which represent $4.6 \%$ of the population of the state. This region is entirely constituted of the Amazon rainforest biome, covering a total area of $111,849.70 \mathrm{~km}^{2}$ and despite being safeguarded by numerous laws, suffers intense exploitation by pastoral activities [4].

Despite the great advances achieved by science, infectious diseases are still among the ten main causes of death worldwide, and it is estimated that the so-called 'super-microorganisms' alone will be responsible for over 10 million deaths by 2050, making imperative the search for alternative treatments to infectious diseases which do not respond to most modern antibiotics [5].

These growing needs for more effective and safer antimicrobial agents have stimulated the renewal of multidisciplinary investigation on natural products, in which new approaches, combined with traditional techniques, are potentiating the tracking of substances which present antimicrobial activities, as well as the identification of the molecular targets responsible for their effects, many of which present novel mechanisms of action [6].

Reactive oxygen species (ROS) are generated as part of the organism metabolism and normal physiological processes and there are endogenous antioxidant systems that help in cushioning the deleterious effects that go with their excessive levels [7]. However, oxidative stress occurs when the ROS overwhelm the cellular antioxidant defence system, either by increased ROS generation or by decreased cellular antioxidant capacity. The threat of oxidative stress is so real as it results in macromolecular damage implicated in many diseases including but not limited to sickle-cell disease [8], 
atherosclerosis, diabetes, carcinogenesis, and inflammatory diseases, just to mention but few [7].

Among the active compounds sought-after in plants, special focus is given to those that show antioxidant activity, being capable of inactivating ROS, which are intimately related to the aetiology of numerous illnesses [9].

In this context, polyphenols constitute one of the largest and widely distributed groups of natural products in the plant kingdom [10]. They are capable of scavenging ROS and may have therapeutic health effects for a variety of illnesses, including antimicrobial properties [11]. More recently, specific molecular targets for various polyphenols have been described and have resulted in renewed scientific interests in the polyphenols as therapeutic agents [9-10].

The methods used for estimation of antioxidant capacities of the plant extracts were based on their simplicity, low cost, and reproducibility. In this case, we employed the three commonly utilized antioxidant assays, namely DPPH, FRAP and NO scavenging assays to verify the antioxidant potential of each extract [12].

Thus, the preliminary in vitro screening of antimicrobial activity of plants popularly used to treat infections serves as a guide for the selection of substantial candidates for future phytochemical and pharmacological research aimed at the development of new antimicrobial prototypes.

Based on our recent ethnopharmacological surveys of medicinal plants from the state of Mato Grosso, Brazil [1-13] and literature review [14], we carried out screening of selected plants for their antibacterial, antioxidative and antiradical activities. We also evaluated the linear correlation between the selected secondary metabolites classes present in the extracts to their in vitro antioxidant and anti-radical activities.

\section{MATERIALS AND METHODS}

\section{Plant material}

The 26 species of plants utilized in the bioassays were selected through an ethnobotanical survey carried out between the years 2010-2013 as reported by Bieski et al. [1]. The study involved ( $\mathrm{n}=$ sampling number) 365 informants selected based on statistical sampling, calculated per the total population of 139,524 inhabitants of the 7 municipals of Juruena valley, north-western Mato Grosso, in the Legal Amazon region [1]. The access to samples of the genetic patrimony was authorized by Conselho Nacional de Desenvolvimento Científico e Tecnológico (CNPq), under the number 010728/2013-9.

The selection of medicinal plants mentioned by the population of Juruena valley for the treatment of infections was made after ethnobotanical data analysis and literature review. The ethnobotanical survey data was obtained via the application of a semi-structured questionnaire, containing the descriptors: infection, antibiotic, pneumonia, bronchitis, gastritis, diarrhoea, vaginal discharge, syphilis, impetigo, conjunctivitis, venereal disease, gonorrhoea, boils, inflammation, fever, wound, wound healing, fungi, mycoses, skin spots, mouth sore, thrush, itching, nail infection, chilblains, and athlete's foot [1-11]. Voucher specimens were deposited and identified at the UFMT Herbarium, under the supervision of a botanist and curator Prof. Germano Guarim Neto.

\section{Microbial organisms}

All the microorganisms used were representative from American Type Culture Collection (ATCC) and obtained through Oswaldo Cruz Foundation (Fiocruz, Rio de Janeiro, Brazil), namely: Enterococcus faecalis (29212), Staphylococcus aureus (25923), Staphylococcus epidermidis (12228), Streptococcus pyogenes (19615), Bacillus subitilis (6633), Escherichia coli (25922), Klebsiella pneumoniae (13883), Pseudomonas aeruginosa (27853), Salmonella typhimurium (14028), Shigella flexneri (12022), Helicobacter pylori (43504 (VacA and CagA positive), Candida albicans (10231), fluconazole-resistant C. albicans (64550), C. parapsilosis (22019), C. tropicalis (750), Cryptococcus neoformans (32045), C. glabrata (9030), Aspergillus fumigatus (46640), A. niger (10535), A. parasiticus (15517), A. terreus (7860), Penicillium verrucosum (10513), Trichophyton mentagrophytes (9533), T. rubrum (28189) and Microsporum gypseum (14383).

\section{Chemicals and reagents}

2,2-diphenyl-1-picrylhydrazyl (DPPH), brain heart infusion media (BHI), and Müller-Hinton agar, Skirrow's medium, amphotericin B, foetal bovine serum (FBS), Sabourad broth, clarithromycin, methanol, trichloroacetic acid, ascorbic acid, potassium phosphate buffer, potassium ferricyanide, ferric chloride, quercetin, nitroprusside, phosphate buffer saline, Griess, gallic acid, sodium carbonate, rutin, acetic acid, aluminium chloride, acetate were obtained from Sigma-Aldrich Co., St. Louis, MO, USA. Other chemicals/reagents used were: Ethanol, chloridric acid (Tedia Company, Inc., CA, USA).

\section{Preparation of plant extracts}

Bark, stem bark, branches, leaves, roots, or whole plant were collected, cleaned and dried at room temperature and then ground in a knife mill (Tecnal ${ }^{\circledR}$ Te 625, São Paulo, BR), standardized with a 40 sieve. The resulting powder of each plant was macerated in $70 \%$ ethanol/water solution $(1: 3 \mathrm{v} / \mathrm{v})$, during $7 \mathrm{~d}$ at $24{ }^{\circ} \mathrm{C}$ with daily shaking for homogenization. After filtration, the material was concentrated in rotary evaporator (MA 120, Marconi®, São Paulo, BR), under reduced pressure of $600 \mathrm{mmHg}$ and temperature of $40 \pm 1$ ${ }^{\circ} \mathrm{C}$. The residual solvent was evaporated in an oven (MA035/5, Marconi ${ }^{\circledR}$, São Paulo, BR) at $40 \pm 1{ }^{\circ} \mathrm{C}$ and the hydroethanolic extracts therefore obtained were freeze-dried (LJJ06V, JJ Científica ${ }^{\circledR}$, São Paulo, BR) and kept in amber flask at $4{ }^{\circ} \mathrm{C}$. At the time of the assays, the extracts' stock solutions were dissolved in $2 \%$ DMSO.

\section{Antimicrobial activity test}

\section{Microdilution in broth}

The minimum inhibitory concentration (MIC) was determined by microdilution in broth as described in Clinical and Laboratory Standards Institute (CLSI) guidelines [15, 16]. Bacterial isolates were cultured in brain heart infusion media (BHI), except for $H$. pylori where Skirrow's supplement was added to BHI medium (vancomycin $10 \mu \mathrm{g} / \mathrm{ml}$, trimethoprim $5 \mu \mathrm{g} / \mathrm{ml}$, polymyxin B 2.5 $\mathrm{U} / \mathrm{ml})$, amphotericin B $(5 \mu \mathrm{g} / \mathrm{ml})$ and foetal bovine serum (FBS) 10 $\%$. Microdilution in Sabourad broth was employed for the MIC investigation of fungi.

The hydroethanolic extracts were solubilized in culture media for concentrations ranging from $800-6.25 \mu \mathrm{g} / \mathrm{ml}$. The bacterial inoculum was adjusted to the concentration of $1 \times 10^{8} \mathrm{CFU} / \mathrm{ml}(0.5 \mathrm{in}$ McFarland scale), except for H. pylori, which was adjusted to the concentration of $6 \times 10^{8} \mathrm{CFU} / \mathrm{ml}$ ( 2 on McFarland scale). Filamentous fungi and yeast-like fungi were adjusted to the concentration of $5 \mathrm{x}$ $10^{3} \mathrm{CFU} / \mathrm{ml}$. Clarithromycin $(50-0.195 \mu \mathrm{g} / \mathrm{ml})$ was used as the standard antibacterial drug and amphotericin B (32-0.125 $\mu \mathrm{g} / \mathrm{ml})$ as the standard antifungal drug.

These microorganisms were incubated at $37^{\circ} \mathrm{C}$; the bacteria for $1-2 \mathrm{~d}$, apart from $H$. pylori, which remained incubated for 3-5 d. The yeastlike fungi were incubated for 2-3 d, the filamentous fungi for $3 \mathrm{~d}$ and the dermatophyte filamentous fungi were incubated for between 3 and $21 \mathrm{~d}$.

MICs were determined based on the turbidity of microplate wells, read in a spectrophotometer at $450 \mathrm{~nm}$ (Thermo Scientific ${ }^{\mathrm{TM}}$, Multiskan $^{\mathrm{TM}}$, New Hampshire, USA), and confirmatory assessment was conducted using resazurin as an indicator of redox. MIC was considered the concentration that completely impedes microbial growth.

MIC values $<100 \mu \mathrm{g} / \mathrm{ml}, 100 \leq \mathrm{MIC} \leq 500 \mu \mathrm{g} / \mathrm{ml}, 500<$ MIC $\leq 800$ $\mu \mathrm{g} / \mathrm{ml}$, and $\mathrm{MIC}>800 \mu \mathrm{g} / \mathrm{ml}$ were considered of good, moderate, weak and without activity, respectively based on the modified classification of Holetz et al. [17].

\section{Determination of the MBC and MFC}

The potential bactericidal effects of the extracts were determined 
per the method of Mbah et al. [18]. An aliquot $(10 \mu \mathrm{l})$ of bacterial cells from the MIC test plate was subcultured on solid Müller-Hinton agar by making streaks on the surface of the agar and incubating at $37{ }^{\circ} \mathrm{C}$ for $1-2 \mathrm{~d}$, and for plates where there was no visible fungal growth, the same was plated on Sabouraud agar and was incubated for $2 \mathrm{~d}$ in the case of yeast-like fungi, $3 \mathrm{~d}$ for filamentous fungi or 3 $21 \mathrm{~d}$ for the dermatophytes. The concentration of the wells inoculated with MIC which showed no bacterial growth was recorded as MBC and those that presented bacterial growth were considered bacterio-static. In the case of the fungi, test concentration without growth at all is considered as the MFC. All assays were carried out in independent triplicates.

\section{In vitro antioxidant activity}

\section{DPPH assay}

The antiradical activity of the extracts was evaluated using DPPH [19]. In this assay, compounds that present antioxidant activity act as electron donors, causing the reduction or neutralization of the DPPH radical that can be verified through the decrease in absorbance. In a 96-well microplate, $100 \mu \mathrm{l}$ of different concentrations of the extracts (800-6.25 $\mu \mathrm{g} / \mathrm{ml}), 100 \mu \mathrm{l}$ of $50 \mu \mathrm{M}$ $\mathrm{DPPH}$, both diluted in methanol/water solution (50\%). After 30 min, the reading was carried out in a microplate reader at a wavelength of $540 \mathrm{~nm}$. Ascorbic acid $(100-0.39 \mu \mathrm{g} / \mathrm{ml})$ was used as the standard.

\section{FRAP assay}

To determine the antioxidant activity of the extracts based on their capacity to reduce ferric ion $\left(\mathrm{Fe}^{+3}\right)$ into ferrous ion $\left(\mathrm{Fe}^{+2}\right)$ [20], extracts at concentrations ranging from $800-6.25 \mu \mathrm{g} / \mathrm{ml}$ and ascorbic acid (50-0.39 $\mu \mathrm{g} / \mathrm{ml})$ were dissolved in $50 \%$ aqueous methanol solution and FRAP assays were conducted. In each well of the 96 wells plate, $30 \mu \mathrm{l}$ of each plant extract concentration or ascorbic acid was added. Subsequently, $40 \mu \mathrm{l}$ each of potassium phosphate buffer $(0.2 \mathrm{M}, \mathrm{pH} 7.2)$ and potassium ferricyanide $(1 \%$ $\mathrm{w} / \mathrm{v}$ ) were added. The reaction mixtures were incubated at $50{ }^{\circ} \mathrm{C}$ for $20 \mathrm{~min}$. After the incubation period, $40 \mu \mathrm{l}$ of trichloroacetic acid $(10 \% \mathrm{w} / \mathrm{v}), 150 \mu \mathrm{l}$ of distilled water and $30 \mu \mathrm{l}$ ferric chloride $(0.1 \%$ $\mathrm{w} / \mathrm{v}$ ) were added, followed by a second incubation at room temperature for $30 \mathrm{~min}$ in the dark. Absorbance was measured at $630 \mathrm{~nm}$ using a microplate reader.

\section{NO assay}

Nitrite $\left(\mathrm{NO}_{2}\right.$-) formation inhibition was used for the evaluation of the antioxidant potential of the extracts, per the modified method of Sreejayan and Rao [21]. $100 \mu \mathrm{l}$ of each extract $(800-6.25 \mu \mathrm{g} / \mathrm{ml})$ or quercetin $(50-0.39 \mu \mathrm{g} / \mathrm{ml})$ were added to a 96-well microplate, containing sodium nitroprusside at $5 \mathrm{mmol}$ in phosphate buffer saline. After incubation at $25^{\circ} \mathrm{C}$ for $150 \mathrm{~min}, 100 \mu \mathrm{l}$ of Griess reagent were added to each well and absorbance measurements carried out in a microplate reader at $540 \mathrm{~nm}$.

\section{Quantitative analysis of selected metabolic classes}

\section{Total phenolic content}

Total phenolic content was quantified using the Folin-Ciocalteu method [22]. Methanolic solutions $(0.2 \mathrm{ml})$ of the extracts $(1 \mathrm{mg} / \mathrm{ml}$, $\mathrm{w} / \mathrm{v}$ ) or the standard used (Gallic acid, $1.0-0.1 \mathrm{mg} / \mathrm{ml}, \mathrm{w} / \mathrm{v}$ ) were mixed with Folin-Ciocalteu reagent $(0.5 \mathrm{ml}$ of $10 \%$, v/v), sodium carbonate $(1 \mathrm{ml}$ of $75 \%, \mathrm{w} / \mathrm{v})$ and Milli-Q water $(8.3 \mathrm{ml})$. The mixture was gently agitated and kept for $30 \mathrm{~min}$ in the dark. The absorbance was measured at $760 \mathrm{~nm}$ using a UV-visible spectrophotometer (Genesys 5, Spectronic $₫$, Texas, USA). Total phenolic was determined by interpolation of the absorbance of the samples against a calibration curve constructed with different concentrations of gallic acid in Milli-Q water $(y=0.0747 x+0.01471$, with $\left.R^{2}=0.9874\right)$. The result was expressed as mg tannic acid equivalents (TAE) per gram of the extracts (mg TAE/g).

\section{Flavonoid content}

Determination of flavonoid content was estimated by a colorimetric method based on the formation of the flavonoid-aluminium complex
[22] with slight modifications. Briefly, $0.5 \mathrm{ml}$ of methanolic solutions of the extracts $(1 \mathrm{mg} / \mathrm{ml} \mathrm{w} / \mathrm{v})$ or standard (rutin, $10-1 \mathrm{mg} / \mathrm{ml} \mathrm{w} / \mathrm{v}$ ) was mixed with an aqueous solution of $0.5 \mathrm{ml}$ of $60 \%$ acetic acid, $2 \mathrm{ml}$ methanolic solution of $20 \%$ pyridine (v/v), $1 \mathrm{ml}$ of $5 \%$ aluminium chloride $(\mathrm{w} / \mathrm{v})$ and $6 \mathrm{ml}$ of Milli- $\mathrm{Q}$ water. The mixture was gently stirred and kept for $30 \mathrm{~min}$ in the dark and its absorbance was then measured at $420 \mathrm{~nm}$ using a spectrophotometer. The total flavonoid contents were determined by extrapolating the absorbance of the samples against a calibration curve constructed with different concentrations of the rutin standard $\left(\mathbf{y}=0.0419 \mathbf{x}+0.0044\right.$, with $\left.R^{2}=0.9977\right)$ and expressed as milligrammes of rutin equivalents (RE) per gram of the extracts (mg $\mathrm{RE} / \mathrm{g}$ ).

\section{Coumarins content}

To determine the concentration of coumarins, the colorimetric method [22] was employed. Briefly, to the extracts $(1 \mathrm{mg} / \mathrm{ml}) 1 \mathrm{ml}$ of distilled water, $0.5 \mathrm{ml}$ of $5 \%$ solution of lead acetate and $7 \mathrm{ml}$ of distilled water. Then, $2 \mathrm{ml}$ of this solution was transferred to tubes containing $8 \mathrm{ml}$ of $0.1 \mathrm{M}$ chloridric acid. The solution was kept in the dark for 30 min and the absorbance was measured using a UV-light spectrophotometer at $320 \mathrm{~nm}$, using distilled water as a blank. The results were expressed in $\mathrm{mg}$ of coumarin per gram of the extract (mg CE/g), using the equation of the standard curve: $\mathbf{y}=$ $0.0935 \mathrm{x}+0.0708$, with $\mathrm{R}^{2}=0.9927$.

\section{Correlation of antioxidant against phenolic contents}

To assess the relationship between total phenolic, flavonoids or coumarins contents and antioxidant or antiradical capacities (except NO assay, in which extracts had no $\mathrm{IC}_{50}$ ) of the extracts, a linear correlation analysis was performed using the $\mathrm{IC}_{50}$ of each extract.

\section{Data analysis}

For the organization and analysis of the date, the GraphPad Prism software version 5.01 was employed. The antimicrobial results were expressed in terms of MIC and the results of the antioxidant assays were expressed in terms of $\mathrm{IC}_{50}$ obtained from a linear regression curve, relating the percentage of antioxidant activity to the tested concentrations. The results of the quantitative analysis of some selected metabolic classes were expressed in terms of mean $\pm \mathrm{SD}$ calculated through the standard curve obtained for each representative of the analysed metabolic class. Shapiro-Wilk test was conducted to evaluate if the samples originated from a normal population. For the study of the correlation between the antioxidant activity of the extracts in the DPPH and FRAP assays with Total phenols and Flavonoids concentrations, Pearson's correlation coefficient was used, since it measures the degree of linear correlation and the quantitative variables were from a normal population. In the case of correlation between the coumarins with antioxidant activity against DPPH and FRAP, Spearman correlation coefficient was used, which is a measure of non-parametric correlation. If so, the presence or absence of correlation was evaluated using Spearman or Pearson test correlation test. Values of $p<0.05$ were considered significant.

\section{RESULTS AND DISCUSSION}

The choice of maceration of the plant powder in a hydroethanolic solvent in the present study was based on many factors. The use of this type of extract in ethnopharmacological and ethnobotanical related studies and others, particularly for plants having more than one form of preparations (see table 1) has been a standard practice.

Besides, the use of the hydroethanolic solution in the preparation of plants extracts is widespread in Brazil, as can be seen in many studies by $[1,13,17-18,24,34]$. In fact, this form of preparation constitutes one of the different forms recognized in the Brazilian pharmacopoeia. We also considered the fact that hydroethanolic solvent can extract both the constituents extracted by the aqueous solvent and including some other non-polar constituents. Although there are significant variations among extracts obtained using different solvents, the greater extractive ability of ethanol is well documented in the literature. These includes among others: its 
polarity is close to that of water, its allows for better conservation of the material being extracted at a milder temperature $\left(40^{\circ} \mathrm{C}\right)$ in the preparation of lyophilized extract, and its extract more efficiently the active pharmacological constituents [24]. Table 1 shows a summary of the ethnomedicinal uses of the plants and the form of preparations of each plant.

\section{Antibacterial activity}

The antibacterial effects of the extracts are presented in table 2 . Among the 26 tested extracts, 18 were active against at least one bacterial strain of the tested panel. Three hydroethanolic extracts presented broad spectra of activity, namely HEPg, $H$. coronarium (HEHc) and HEHm.

Table 1: A summary of ethnomedicinal uses of the plants screened for the antimicrobial activities, forms of preparations and related references

\begin{tabular}{|c|c|c|c|c|c|c|}
\hline Species/Extract & Family & $\begin{array}{l}\text { Vernacular } \\
\text { name }\end{array}$ & Ethnomedicinal uses & $\begin{array}{l}\text { Parts } \\
\text { used }\end{array}$ & Forms of preparation & References \\
\hline $\begin{array}{l}\text { Aristolochia } \\
\text { cymbifera Mart. \& } \\
\text { Zucc./HEAc }\end{array}$ & Aristolochiaceae & $\begin{array}{l}\text { Cipó-mil- } \\
\text { homem }\end{array}$ & $\begin{array}{l}\text { Wound healing, circulation, } \\
\text { blood depurative, natural } \\
\text { viagra, local pain, malaria, } \\
\text { stomach, liver, indigestion, } \\
\text { gastrointestinal problems, } \\
\text { worm, menstrual cramps, } \\
\text { menstruation, partum } \\
\text { relapse, antibiotic, } \\
\text { inflammation, rheumatism, } \\
\text { bladder, diuretic, kidneys }\end{array}$ & $\begin{array}{l}\text { Stem } \\
\text { bark }\end{array}$ & $\begin{array}{l}\text { Decoction, infusion, or tea; } \\
\text { maceration; } \\
\text { poultice/compress }\end{array}$ & [1] \\
\hline $\begin{array}{ll}\text { Phanera } & \text { glabra } \\
\text { Jacq./HEPg } & \end{array}$ & Fabaceae & $\begin{array}{l}\text { Cipó-escada- } \\
\text { de-macaco }\end{array}$ & $\begin{array}{l}\text { Frigidity, allergy, } \\
\text { rheumatism, infections }\end{array}$ & $\begin{array}{l}\text { Stern } \\
\text { bark }\end{array}$ & Decoction and infusion & [1] \\
\hline $\begin{array}{lr}\text { Bertholletia } & \text { excelsa } \\
\text { Bonpl. } & \text { ex } \\
\text { Spreng./HEBe }\end{array}$ & Lecythidaceae & $\begin{array}{l}\text { Castanha-do- } \\
\text { brasil }\end{array}$ & $\begin{array}{l}\text { Wound healing, impetigo, spots } \\
\text { on the skin, white cloth, skin, } \\
\text { diabetic, malaria, diarrhoea, } \\
\text { liver, kidney disease, } \\
\text { cholesterol, blood depurative, } \\
\text { heart stimulant, restorative, } \\
\text { insomnia, nutritious, varicose } \\
\text { veins kidneys }\end{array}$ & Bark & $\begin{array}{l}\text { Decoction and infusion } \\
\text { maceration; salad }\end{array}$ & [1] \\
\hline $\begin{array}{lr}\text { Brunfelsia } & \text { uniflora } \\
\text { (Pohl) } & \text { D. } \\
\text { Don/HEBu } & \\
\end{array}$ & Solanaceae & $\begin{array}{l}\text { Primavera, } \\
\text { Macaé }\end{array}$ & Rheumatism & Roots & Maceration & [1] \\
\hline $\begin{array}{l}\text { Cariniana rubra } \\
\text { Gardner/HECr }\end{array}$ & Lecythidaceae & Jequitiba & Kidneys & Bark & Infusion & [1] \\
\hline $\begin{array}{l}\text { Cedrela odorata } \\
\text { L./HECo }\end{array}$ & Meliaceae & Cedro-rosa & $\begin{array}{l}\text { Malaria, intestinal infection, } \\
\text { intoxication, poor digestion, } \\
\text { kidneys }\end{array}$ & Bark & Decoction maceration. & [1] \\
\hline $\begin{array}{l}\text { Dysphania } \\
\text { ambrosioides } \\
\text { L./HEDa }\end{array}$ & Amaranthaceae & $\begin{array}{l}\text { Erva-de- } \\
\text { santa-maria }\end{array}$ & $\begin{array}{l}\text { wound healing, injuries, } \\
\text { bruise, blow, bone } \\
\text { regeneration, Local pain, } \\
\text { stomach, gastritis, hepatitis, } \\
\text { intestine (infection), } \\
\text { roundworms, worm, } \\
\text { antibiotic, flu, inflammation, } \\
\text { bone fracture, swelling twist }\end{array}$ & Leaves & $\begin{array}{l}\text { Decoction infusion } \\
\text { maceration; salad; syrup }\end{array}$ & [1] \\
\hline $\begin{array}{l}\text { Cordia } \\
\text { Lam./HECn }\end{array}$ & Boraginaceae & $\begin{array}{l}\text { Cipó- } \\
\text { cabeludo }\end{array}$ & Wound healing; ulcer & Leaves & Infusion & [1] \\
\hline $\begin{array}{ll}\text { Cymbopogon } & \\
\text { citratus } & \text { (DC.) } \\
\text { Stapf/HECc } & \end{array}$ & Poaceae & $\begin{array}{l}\text { Capim- } \\
\text { cidreira }\end{array}$ & $\begin{array}{l}\text { Calmative, depression, blood } \\
\text { depurative, stress, } \\
\text { hypertension, insomnia, } \\
\text { depression, stomach, local } \\
\text { pain, digestive problems, } \\
\text { stomach, bronchitis, flu, } \\
\text { infection in throat, pneumonia }\end{array}$ & Leaves & Decoction infusion & [1] \\
\hline $\begin{array}{l}\text { Cyperus corymbosus } \\
\text { Rottb. (rh)/HECcy }\end{array}$ & Cyperaceae & Junco & Rheumatism & Rhizome & $\begin{array}{ll}\text { Decoction } & \text { infusion } \\
\text { maceration }\end{array}$ & [1] \\
\hline $\begin{array}{l}\text { Desmoncus } \\
\text { orthacanthos Mart. } \\
\text { (bl)/HEDo }\end{array}$ & Arecaceae & $\begin{array}{l}\text { Cerca-onça, } \\
\text { coquinho }\end{array}$ & Rheumatism, skin infections & $\begin{array}{l}\text { Branches } \\
\text { and } \\
\text { leaves }\end{array}$ & $\begin{array}{l}\text { Decoction maceration; } \\
\text { cataplasm/compression }\end{array}$ & {$[1,14]$} \\
\hline $\begin{array}{l}\text { Dichorisandra } \\
\text { hexandra (Aubl.) } \\
\text { C.B.Clarke/HEDh }\end{array}$ & Commelinaceae & $\begin{array}{l}\text { Cana-de- } \\
\text { macaco }\end{array}$ & $\begin{array}{l}\text { Dehydration, wound healing, } \\
\text { local pain, poor digestion, } \\
\text { column, inflammation, urinary } \\
\text { congestion, diuretic, kidney } \\
\text { infection, kidneys }\end{array}$ & Leaves & $\begin{array}{ll}\text { Decoction } & \text { infusion } \\
\text { maceration } & \end{array}$ & [1] \\
\hline $\begin{array}{lr}\text { Digitaria } & \text { insularis } \\
(\mathrm{L} .) & \text { Fedde } \\
\text { Ekman/HEDi }\end{array}$ & Poaceae & $\begin{array}{l}\text { Campim- } \\
\text { amargoso }\end{array}$ & $\begin{array}{l}\text { Wound healing, wounds, } \\
\text { local pain }\end{array}$ & Leaves & $\begin{array}{l}\text { Cataplasm/compression; } \\
\text { bath }\end{array}$ & [1] \\
\hline $\begin{array}{l}\text { Eleusine indica (L.) } \\
\text { Gaertn/HEEi }\end{array}$ & Poaceae & $\begin{array}{l}\text { Capim-pé- } \\
\text { de-galinha }\end{array}$ & $\begin{array}{l}\text { Wound healing, bruise, poor } \\
\text { circulation, local pain, virtual, } \\
\text { worm, uterus, antibiotic, } \\
\text { bronchitis, flu, pneumonia, }\end{array}$ & Leaves & $\begin{array}{l}\text { Decoction } \\
\text { maceration }\end{array}$ & [1] \\
\hline
\end{tabular}




\begin{tabular}{|c|c|c|c|c|c|c|}
\hline & & & $\begin{array}{l}\text { respiratory problems, cough, } \\
\text { kidneys }\end{array}$ & & & \\
\hline $\begin{array}{l}\text { Gossypium hirsutum } \\
\text { L./HEGi }\end{array}$ & Malvaceae & $\begin{array}{l}\text { Algodão- } \\
\text { roxo }\end{array}$ & $\begin{array}{l}\text { Infection in the ovaries, } \\
\text { uterine infection, postpartum, } \\
\text { throat, kidneys }\end{array}$ & Leaves & $\begin{array}{ll}\text { Decoction } & \text { infusion } \\
\text { maceration, bath } & \end{array}$ & [1] \\
\hline $\begin{array}{l}\text { Hedychium } \\
\text { coronarium } \\
\text { Koenig/HEHc } \\
\end{array}$ & Zingiberaceae & $\begin{array}{l}\text { Gengibre-do- } \\
\text { mato }\end{array}$ & Rheumatism & Rhizome & Decoction & {$[1]$} \\
\hline $\begin{array}{l}\text { Hevea microphylla } \\
\text { Ule/HEHm }\end{array}$ & Euphorbiaceae & Barriguda & Ulcer & Branches & Maceration & {$[1]$} \\
\hline $\begin{array}{l}\text { Jacaranda } \\
\text { cuspidifolia } \\
\text { Mart./HEJc } \\
\end{array}$ & Bignoniaceae & Caroba & $\begin{array}{l}\text { Wound healing; blood } \\
\text { depurative, kidney stones }\end{array}$ & $\begin{array}{l}\text { Branches } \\
\text { and } \\
\text { leaves }\end{array}$ & $\begin{array}{ll}\text { Decoction, } & \text { infusion } \\
\text { maceration, bath } & \end{array}$ & {$[1]$} \\
\hline $\begin{array}{l}\text { Manihot esculenta } \\
\text { Crantz/HEMt }\end{array}$ & Euphorbiaceae & Mandioca & Itching, antibiotic & Leaves & Infusion bath & {$[1]$} \\
\hline $\begin{array}{lr}\text { Maytenus ilicifolia } \\
\text { Mart. } \\
\text { Reissek/HEMi }\end{array}$ & Moraceae & $\begin{array}{l}\text { Espinheira- } \\
\text { santa }\end{array}$ & $\begin{array}{l}\begin{array}{l}\text { Wound healing, stomach, } \\
\text { gastritis, } \\
\text { inflammation, kidneys }\end{array} \\
\text { antibiotic, }\end{array}$ & Bark & Infusion & [1] \\
\hline $\begin{array}{l}\text { Parodiolyra } \\
\text { micrantha (Kunth) } \\
\text { Davidse and } \\
\text { Zuloaga/HEPm }\end{array}$ & Poaceae & Bambuzinho & Stomach, kidneys & Leaves & Decoction infusion & {$[1]$} \\
\hline $\begin{array}{l}\text { Philodendron } \\
\text { acutatum } \\
\text { Schott/HEPa }\end{array}$ & Araceae & Cipó-imbé & Erysipelas, back pain & $\begin{array}{l}\text { Whole } \\
\text { plant }\end{array}$ & $\begin{array}{l}\text { Decoction } \\
\text { cataplasm/compression }\end{array}$ & {$[1]$} \\
\hline $\begin{array}{l}\text { Renealmia } \\
\text { alpinia (Rottb.) } \\
\text { Maas/HERa }\end{array}$ & Zingiberaceae & $\begin{array}{l}\text { Pacová, } \\
\text { Gengibre-do- } \\
\text { mato }\end{array}$ & Rheumatism & Rhizome & Maceration & {$[1]$} \\
\hline $\begin{array}{l}\text { Smilax brasiliensis } \\
\text { Spreng./HESb }\end{array}$ & Smilacaceae & Japecanga & $\begin{array}{l}\text { Wound healing, blood } \\
\text { depurative, inflammation, } \\
\text { rheumatism }\end{array}$ & $\begin{array}{l}\text { Branches } \\
\text { and } \\
\text { leaves }\end{array}$ & Decoction & {$[1]$} \\
\hline $\begin{array}{l}\text { Spondias } \\
\text { mombin L./HESm }\end{array}$ & Anacardiaceae & $\begin{array}{l}\text { Cajazinho, } \\
\text { caju-açu-da- } \\
\text { mata }\end{array}$ & Wound healing, diarrhoea & Leaves & Decoction infusion bath & [1] \\
\hline $\begin{array}{l}\text { Trema micrantha } \\
\text { (L.) Blume/HETm }\end{array}$ & Cannabaceae & $\begin{array}{l}\text { Grandiuva, } \\
\text { periquiteiro }\end{array}$ & $\begin{array}{l}\text { Insect bite, inflammation, } \\
\text { heartburn, ulcer }\end{array}$ & Bark & & \\
\hline
\end{tabular}

Table 2: Evaluation of the in vitro antibacterial activity of the hydroethanolic extracts of medicinal plants used for the treatment of infections

\begin{tabular}{|c|c|c|c|c|c|c|c|c|c|c|c|}
\hline \multirow[t]{3}{*}{ Species/extract } & \multicolumn{11}{|c|}{ aMinimum inhibitory concentration (MIC, $\mu \mathrm{g} / \mathrm{ml}$ ) } \\
\hline & \multicolumn{6}{|c|}{ Gram-negative } & \multicolumn{5}{|c|}{ Gram-positive } \\
\hline & $E c$ & $K p$ & $P a$ & St & $S f$ & Hp & $E f$ & $S a$ & $S p$ & Se & Bs \\
\hline Aristolochia cymbifera Mart. and Zucc. (bl)/HEAc & $\begin{array}{l}>80 \\
0\end{array}$ & $\begin{array}{l}>80 \\
0\end{array}$ & $\begin{array}{l}>80 \\
0\end{array}$ & $\begin{array}{l}>80 \\
0\end{array}$ & $\begin{array}{l}>80 \\
0\end{array}$ & 400 & $\begin{array}{l}>80 \\
0\end{array}$ & $\begin{array}{l}>80 \\
0\end{array}$ & $\begin{array}{l}>80 \\
0\end{array}$ & $\begin{array}{l}>80 \\
0\end{array}$ & $\begin{array}{l}>80 \\
0\end{array}$ \\
\hline Phanera glabra (Jacq.) Vaz (sb) / HEPg & 800 & 25 & 800 & 800 & 800 & $\begin{array}{l}>80 \\
0\end{array}$ & 200 & $\begin{array}{l}>80 \\
0\end{array}$ & 400 & 800 & 800 \\
\hline Bertholletia excelsa Bonpl. (b)/HEBe & $\begin{array}{l}>80 \\
0\end{array}$ & $\begin{array}{l}>80 \\
0\end{array}$ & $\begin{array}{l}>80 \\
0\end{array}$ & $\begin{array}{l}>80 \\
0\end{array}$ & $\begin{array}{l}>80 \\
0\end{array}$ & 200 & $\begin{array}{l}>80 \\
0\end{array}$ & 400 & 200 & $\begin{array}{l}>80 \\
0\end{array}$ & $\begin{array}{l}>80 \\
0\end{array}$ \\
\hline Brunfelsia uniflora (Pohl) D. Don (r)/HEBu & $\begin{array}{l}>80 \\
0\end{array}$ & $\begin{array}{l}>80 \\
0\end{array}$ & $\begin{array}{l}>80 \\
0\end{array}$ & $\begin{array}{l}>80 \\
0\end{array}$ & $\begin{array}{l}>80 \\
0\end{array}$ & $\begin{array}{l}>80 \\
0\end{array}$ & $\begin{array}{l}>80 \\
0\end{array}$ & $\begin{array}{l}>80 \\
0\end{array}$ & $\begin{array}{l}>80 \\
0\end{array}$ & $\begin{array}{l}>80 \\
0\end{array}$ & $\begin{array}{l}>80 \\
0\end{array}$ \\
\hline Cariniana rubra Gardner ex Miers (b)/HECr & $\begin{array}{l}>80 \\
0\end{array}$ & $\begin{array}{l}>80 \\
0\end{array}$ & $\begin{array}{l}>80 \\
0\end{array}$ & $\begin{array}{l}>80 \\
0\end{array}$ & $\begin{array}{l}>80 \\
0\end{array}$ & 100 & 400 & 200 & 400 & $\begin{array}{l}>80 \\
0\end{array}$ & $\begin{array}{l}>80 \\
0\end{array}$ \\
\hline Cedrela odorata L. (b)/HECo & $\begin{array}{l}>80 \\
0\end{array}$ & $\begin{array}{l}>80 \\
0\end{array}$ & $\begin{array}{l}>80 \\
0\end{array}$ & $\begin{array}{l}>80 \\
0\end{array}$ & 800 & $\begin{array}{l}>80 \\
0\end{array}$ & $\begin{array}{l}>80 \\
0\end{array}$ & 400 & $\begin{array}{l}>80 \\
0\end{array}$ & $\begin{array}{l}>80 \\
0\end{array}$ & $\begin{array}{l}>80 \\
0\end{array}$ \\
\hline Dysphania ambrosioides L. (l)/HEDa & $\begin{array}{l}>80 \\
0 \\
\end{array}$ & $\begin{array}{l}>80 \\
0\end{array}$ & $\begin{array}{l}>80 \\
0 \\
\end{array}$ & $\begin{array}{l}>80 \\
0 \\
\end{array}$ & $\begin{array}{l}>80 \\
0 \\
\end{array}$ & 200 & 400 & $\begin{array}{l}>80 \\
0 \\
\end{array}$ & 400 & 400 & $\begin{array}{l}>80 \\
0\end{array}$ \\
\hline Cordia nodosa Lam. (l)/HECn & $\begin{array}{l}>80 \\
0\end{array}$ & $\begin{array}{l}>80 \\
0\end{array}$ & $\begin{array}{l}>80 \\
0\end{array}$ & 200 & 50 & $\begin{array}{l}>80 \\
0\end{array}$ & $\begin{array}{l}>80 \\
0\end{array}$ & $\begin{array}{l}>80 \\
0\end{array}$ & 400 & 100 & $\begin{array}{l}>80 \\
0\end{array}$ \\
\hline Cymbopogon citratus (DC.) Stapf (I)/HECc & $\begin{array}{l}>80 \\
0\end{array}$ & $\begin{array}{l}>80 \\
0\end{array}$ & $\begin{array}{l}>80 \\
0\end{array}$ & $\begin{array}{l}>80 \\
0\end{array}$ & $\begin{array}{l}>80 \\
0\end{array}$ & $\begin{array}{l}>80 \\
0\end{array}$ & $\begin{array}{l}>80 \\
0\end{array}$ & $\begin{array}{l}>80 \\
0\end{array}$ & $\begin{array}{l}>80 \\
0\end{array}$ & $\begin{array}{l}>80 \\
0\end{array}$ & $\begin{array}{l}>80 \\
0\end{array}$ \\
\hline Cyperus corymbosus Rottb. (rh)/ HECcy & $\begin{array}{l}>80 \\
0\end{array}$ & $\begin{array}{l}>80 \\
0\end{array}$ & $\begin{array}{l}>80 \\
0\end{array}$ & $\begin{array}{l}>80 \\
0\end{array}$ & $\begin{array}{l}>80 \\
0\end{array}$ & $\begin{array}{l}>80 \\
0\end{array}$ & $\begin{array}{l}>80 \\
0\end{array}$ & $\begin{array}{l}>80 \\
0\end{array}$ & $\begin{array}{l}>80 \\
0\end{array}$ & $\begin{array}{l}>80 \\
0\end{array}$ & $\begin{array}{l}>80 \\
0\end{array}$ \\
\hline Desmoncus orthacanthos Mart. (bl)/HEDo & $\begin{array}{l}>80 \\
0\end{array}$ & $\begin{array}{l}>80 \\
0\end{array}$ & $\begin{array}{l}>80 \\
0\end{array}$ & $\begin{array}{l}>80 \\
0\end{array}$ & 25 & $\begin{array}{l}>80 \\
0\end{array}$ & $\begin{array}{l}>80 \\
0\end{array}$ & $\begin{array}{l}>80 \\
0\end{array}$ & 200 & $\begin{array}{l}>80 \\
0\end{array}$ & $\begin{array}{l}>80 \\
0\end{array}$ \\
\hline Dichorisandra hexandra (Aubl.) C. B. Clarke (l)/HEDh & $\begin{array}{l}>80 \\
0\end{array}$ & $\begin{array}{l}>80 \\
0\end{array}$ & $\begin{array}{l}>80 \\
0\end{array}$ & $\begin{array}{l}>80 \\
0\end{array}$ & 800 & $\begin{array}{l}>80 \\
0\end{array}$ & $\begin{array}{l}>80 \\
0\end{array}$ & $\begin{array}{l}>80 \\
0\end{array}$ & $\begin{array}{l}>80 \\
0\end{array}$ & $\begin{array}{l}>80 \\
0\end{array}$ & $\begin{array}{l}>80 \\
0\end{array}$ \\
\hline Digitaria insularis (L.) Fedde (l)/HEDi & $\begin{array}{l}>80 \\
0\end{array}$ & $\begin{array}{l}>80 \\
0\end{array}$ & $\begin{array}{l}>80 \\
0\end{array}$ & 800 & 200 & $\begin{array}{l}>80 \\
0\end{array}$ & 200 & $\begin{array}{l}>80 \\
0\end{array}$ & 200 & $\begin{array}{l}>80 \\
0 \\
\end{array}$ & $\begin{array}{l}>80 \\
0\end{array}$ \\
\hline Eleusine indica (L.) Gaertn (l)/HEEi & $\begin{array}{l}>80 \\
0\end{array}$ & $\begin{array}{l}>80 \\
0\end{array}$ & $\begin{array}{l}>80 \\
0\end{array}$ & $\begin{array}{l}>80 \\
0\end{array}$ & $\begin{array}{l}>80 \\
0\end{array}$ & $\begin{array}{l}>80 \\
0\end{array}$ & $\begin{array}{l}>80 \\
0\end{array}$ & $\begin{array}{l}>80 \\
0\end{array}$ & $\begin{array}{l}>80 \\
0\end{array}$ & $\begin{array}{l}>80 \\
0\end{array}$ & $\begin{array}{l}>80 \\
0\end{array}$ \\
\hline Gossypium hirsutum L. (1)/HEGi & $>80$ & $>80$ & $>80$ & $>80$ & $>80$ & $>80$ & $>80$ & $>80$ & 200 & $>80$ & $>80$ \\
\hline
\end{tabular}




\begin{tabular}{|c|c|c|c|c|c|c|c|c|c|c|c|}
\hline & 0 & 0 & 0 & 0 & 0 & 0 & 0 & 0 & & 0 & 0 \\
\hline Hedychium coronarium J. Koenig (rh)/HEHc & $\begin{array}{l}>80 \\
0 \\
\end{array}$ & 200 & $\begin{array}{l}>80 \\
0\end{array}$ & $\begin{array}{l}>80 \\
0\end{array}$ & 100 & $\begin{array}{l}>80 \\
0 \\
\end{array}$ & $\begin{array}{l}>80 \\
0 \\
\end{array}$ & 25 & 100 & 200 & $\begin{array}{l}>80 \\
0 \\
\end{array}$ \\
\hline Hevea microphylla Ule (b)/HEHm & 400 & 400 & $\begin{array}{l}>80 \\
0\end{array}$ & $\begin{array}{l}>80 \\
0\end{array}$ & 400 & $\begin{array}{l}>80 \\
0\end{array}$ & 200 & 400 & $\begin{array}{l}>80 \\
0\end{array}$ & $\begin{array}{l}>80 \\
0\end{array}$ & $\begin{array}{l}>80 \\
0\end{array}$ \\
\hline Jacaranda cuspidifolia Mart. (bl)/HEJc & $\begin{array}{l}>80 \\
0 \\
\end{array}$ & $\begin{array}{l}>80 \\
0\end{array}$ & $\begin{array}{l}>80 \\
0 \\
\end{array}$ & $\begin{array}{l}>80 \\
0\end{array}$ & $\begin{array}{l}>80 \\
0\end{array}$ & 400 & 200 & $\begin{array}{l}>80 \\
0 \\
\end{array}$ & $\begin{array}{l}>80 \\
0\end{array}$ & $\begin{array}{l}>80 \\
0\end{array}$ & $\begin{array}{l}>80 \\
0 \\
\end{array}$ \\
\hline Manihot esculenta Crantz (l)/HEMt & $\begin{array}{l}>80 \\
0\end{array}$ & $\begin{array}{l}>80 \\
0\end{array}$ & $\begin{array}{l}>80 \\
0\end{array}$ & $\begin{array}{l}>80 \\
0\end{array}$ & $\begin{array}{l}>80 \\
0\end{array}$ & $\begin{array}{l}>80 \\
0\end{array}$ & $\begin{array}{l}>80 \\
0\end{array}$ & $\begin{array}{l}>80 \\
0\end{array}$ & $\begin{array}{l}>80 \\
0\end{array}$ & $\begin{array}{l}>80 \\
0\end{array}$ & $\begin{array}{l}>80 \\
0\end{array}$ \\
\hline Maytenus ilicifolia Mart. ex Reissek (b) HEMi & $\begin{array}{l}>80 \\
0\end{array}$ & $\begin{array}{l}>80 \\
0\end{array}$ & $\begin{array}{l}>80 \\
0\end{array}$ & $\begin{array}{l}>80 \\
0\end{array}$ & $\begin{array}{l}>80 \\
0\end{array}$ & $\begin{array}{l}>80 \\
0\end{array}$ & $\begin{array}{l}>80 \\
0\end{array}$ & 800 & $\begin{array}{l}>80 \\
0\end{array}$ & $\begin{array}{l}>80 \\
0\end{array}$ & $\begin{array}{l}>80 \\
0\end{array}$ \\
\hline $\begin{array}{l}\begin{array}{l}\text { Parodiolyra micrantha (Kunth) Davidse \& Zuloaga } \\
\text { (l)/HEPm }\end{array} \\
\end{array}$ & $\begin{array}{l}>80 \\
0 \\
\end{array}$ & $\begin{array}{l}>80 \\
0\end{array}$ & $\begin{array}{l}>80 \\
0\end{array}$ & $\begin{array}{l}>80 \\
0\end{array}$ & $\begin{array}{l}>80 \\
0\end{array}$ & $\begin{array}{l}>80 \\
0\end{array}$ & $\begin{array}{l}>80 \\
0 \\
\end{array}$ & $\begin{array}{l}>80 \\
0\end{array}$ & $\begin{array}{l}>80 \\
0\end{array}$ & $\begin{array}{l}>80 \\
0\end{array}$ & $\begin{array}{l}>80 \\
0\end{array}$ \\
\hline Philodendron acutatum Schott (wp) HEPa & $\begin{array}{l}>80 \\
0 \\
\end{array}$ & $\begin{array}{l}>80 \\
0\end{array}$ & $\begin{array}{l}>80 \\
0\end{array}$ & $\begin{array}{l}>80 \\
0\end{array}$ & $\begin{array}{l}>80 \\
0\end{array}$ & $\begin{array}{l}>80 \\
0\end{array}$ & 200 & 400 & $\begin{array}{l}>80 \\
0 \\
\end{array}$ & $\begin{array}{l}>80 \\
0\end{array}$ & $\begin{array}{l}>80 \\
0 \\
\end{array}$ \\
\hline Renealmia alpinia (Rottb.) Maas (rh)/HERa & $\begin{array}{l}>80 \\
0 \\
\end{array}$ & $\begin{array}{l}>80 \\
0\end{array}$ & $\begin{array}{l}>80 \\
0\end{array}$ & $\begin{array}{l}>80 \\
0\end{array}$ & $\begin{array}{l}>80 \\
0\end{array}$ & $\begin{array}{l}>80 \\
0\end{array}$ & 400 & $\begin{array}{l}>80 \\
0\end{array}$ & 100 & 800 & $\begin{array}{l}>80 \\
0\end{array}$ \\
\hline Smilax brasiliensis Spreng. (bl)/HESb & $\begin{array}{l}>80 \\
0 \\
\end{array}$ & $\begin{array}{l}>80 \\
0\end{array}$ & $\begin{array}{l}>80 \\
0\end{array}$ & $\begin{array}{l}>80 \\
0\end{array}$ & $\begin{array}{l}>80 \\
0\end{array}$ & $\begin{array}{l}>80 \\
0\end{array}$ & 400 & $\begin{array}{l}>80 \\
0\end{array}$ & $\begin{array}{l}>80 \\
0 \\
\end{array}$ & $\begin{array}{l}>80 \\
0\end{array}$ & $\begin{array}{l}>80 \\
0 \\
\end{array}$ \\
\hline Spondias mombin L. (l)/HESm & $\begin{array}{l}>80 \\
0 \\
\end{array}$ & $\begin{array}{l}>80 \\
0\end{array}$ & $\begin{array}{l}>80 \\
0\end{array}$ & $\begin{array}{l}>80 \\
0\end{array}$ & $\begin{array}{l}>80 \\
0\end{array}$ & 200 & 200 & 400 & 800 & $\begin{array}{l}>80 \\
0 \\
\end{array}$ & $\begin{array}{l}>80 \\
0 \\
\end{array}$ \\
\hline Trema micrantha (L.) Blume (bl)/HETm & $\begin{array}{l}>80 \\
0 \\
\end{array}$ & $\begin{array}{l}>80 \\
0\end{array}$ & $\begin{array}{l}>80 \\
0\end{array}$ & $\begin{array}{l}>80 \\
0\end{array}$ & $\begin{array}{l}>80 \\
0\end{array}$ & $\begin{array}{l}>80 \\
0\end{array}$ & 200 & $\begin{array}{l}>80 \\
0\end{array}$ & $\begin{array}{l}>80 \\
0 \\
\end{array}$ & $\begin{array}{l}>80 \\
0\end{array}$ & $\begin{array}{l}>80 \\
0 \\
\end{array}$ \\
\hline \multicolumn{12}{|l|}{ Standard drug } \\
\hline Clarithromycin & 0.39 & 0.39 & 6.25 & 0.78 & 0.78 & 0.39 & 0.39 & 0.39 & 0.39 & 0.39 & 0.39 \\
\hline
\end{tabular}

aObtained by broth microdilution, (b): bark; (bl): branches and leaves; (l) leaves; (rh): rhizome; (r): root (sb): stem bark; (wp): whole plant; Ec: Escherichia coli, Kp: Klebsiella pneumoniae, Pa: Pseudomonas aeruginosa, St: Salmonella typhimurium, Sf: Shigella flexneri, Hp: Helicobacter pylori, Ef: Enterococcus faecalis, Sa: Staphylococcus aureus, Se: Staphylococcus epidermidis, Sp: Streptococcus pyogenes, Bs: Bacillus subtilis, Results expressed as mean of three independent assays.

HEPg demonstrated activity against 9 of the 11 bacteria tested, presenting good antibacterial activity against $K$. pneumoniae (MIC = $25 \mu \mathrm{g} / \mathrm{ml}$ ), moderate against E. faecalis (MIC $=200 \mu \mathrm{g} / \mathrm{ml}$ ) and $S$. pyogenes $(\mathrm{MIC}=400 \mu \mathrm{g} / \mathrm{ml})$, and weak activity $(\mathrm{MIC}=800 \mu \mathrm{g} / \mathrm{ml}$ ) against E. coli, P. aeruginosa, $S$. typhimurium, S. flexneri, $S$. epidermidis and $B$. subtilis. Although the genus Bauhinia is used popularly in the treatment of infections and antimicrobial biological activities have been confirmed for some of its species [25], no studies were found concerning P. glabra antibacterial activity. It is interesting to note that HEPg was more active against $K$. pneumoniae, one of the most common enterobacteria known to cause hospital infections, especially in immunosuppressed patients [26], suggesting its potential in treating infections caused by this bacterium.

HEHc showed good $(\mathrm{MIC}=25 \mu \mathrm{g} / \mathrm{ml}$ ) and moderate $(\mathrm{MIC}=100$ $\mu \mathrm{g} / \mathrm{ml}$ and $200 \mu \mathrm{g} / \mathrm{ml}$ ) activities against $S$. aureus; $S$. flexneri and $S$. pyogenes; $K$. pneumoniae and $S$. epidermidis, respectively. Most studies found in the literature refer to the antimicrobial activities of the essential oil obtained from the rhizome of the plant and the authors employed bacterial strains different from those in this work, apart from $S$. aureus with MIC $=4.2 \mathrm{mg} / \mathrm{ml}$ [27].

In addition, Joshi [28] observed MICs of $7.8 \mu \mathrm{g} / \mathrm{ml}$ against $E$. coli and $S$. aureus and $31.13 \mu \mathrm{g} / \mathrm{ml}$ for $S$. flexneri. These values are 168 folds greater (S. aureus), 3 (S. aureus), and 13 (S. flexneri) times lower, respectively. No activity was observed for HEHc in our study against $E$. coli. Concerning the activity of the essential oil of $H$. coronarium in the studies of Suksathan et al., using disc diffusion method, activities against $S$. aureus, B. subtilis and $E$. coli (inhibition zone $=13 ; 15$ and 9 $\mathrm{mm}$, respectively) were recorded. In the same vein, HEHc demonstrated activity (inhibition zones $>10 \mathrm{~mm}$ ) against $S$. aureus, $S$. epidermidis, E. coli and $P$. aeruginosa for the aqueous and methanolic extract of the leaves and rhizome of $H$. coronarium [29-30]. However, in our study, HEHc was inactive against strains of E. coli, $P$. aeruginosa and B. subtilis.

Reuk-ngam et al. [31], showed the antimicrobial activity of coronarin $\mathrm{D}$, isolated from the rhizomes of $H$. coronarium, with a more potent antibacterial activity than observed for HEHc, with MIC 2 times lower for $S$. aureus and $S$. epidermidis (MIC $=12.5 \mu \mathrm{g} / \mathrm{ml}$ ). No activity was seen against $E$. faecalis by HEHc in our study. These results suggest that coronarin $\mathrm{D}$, may be responsible, at least in part, for the antibacterial activity of this plant. However, there is a need for phytochemical studies to confirm the presence of coronarin D in HEHc.
According to Gobbo-Neto and Lopes [32], there are several factors which may be responsible for the variations in the activity of a plant, among which are variations in the seasons of collections, temperature, water availability, ultraviolet radiation, nutrients availability, atmospheric pollution, mechanical damage, and pathogen attacks. These external differences invariably influence the composition and levels of important secondary metabolites of the plant materials employed in these different studies, in addition to the variations related to methodological approaches in the antimicrobial assays [33].

Moderate antibacterial activity by HEHm was detected against $E$. faecalis $(\mathrm{MIC}=200 \mu \mathrm{g} / \mathrm{ml}$ ), E. coli, K. pneumoniae, S. flexneri and $S$. aureus $(\mathrm{MIC}=400 \mu \mathrm{g} / \mathrm{ml}$ ). These microorganisms are notably related to intestinal diseases, urinary infections, and pneumonia, as well as infections of heart tissue, meningitis, septicaemia, mainly in immunocompromised patients [5]. In literature, most articles found concerning the genus Hevea refers to preliminary investigations of $H$. brasiliensis against clinical isolates of E. coli, K. pneumoniae, $S$. aureus and B. cereus [34]. However, to the best of our knowledge, there are no reports on the antimicrobial activity of $H$. microphylla. Based on these results it will be interesting to carry out further pharmacological and phytochemical studies with HEHm.

Although the spectrum of action of HECn is not as broad as that of HEPg, HEHc and HEHm, it deserves attention for showing activity against two important pathogenic bacteria, namely $S$. flexneri (MIC = $25 \mu \mathrm{g} / \mathrm{ml}$ ), an enterobacteria responsible for between 80-165 million cases of severe dysentery and about 600 thousand deaths annually, and S. epidermidis (MIC $=100 \mu \mathrm{g} / \mathrm{ml}$ ), a frequent pathogenic agent in invasive procedures in hospital environment [535]. There are no previous antibacterial studies with HECn, however activity has been reported for some of its fractions against $S$. aureus and $S$. epidermidis (inhibition halos $=8$ and $15 \mathrm{~mm}$, respectively), but at extremely high concentrations $(125-1000 \mathrm{mg} / \mathrm{ml})$ which according to Holetz et al. criteria, at these concentrations the fractions would be considered inactive, thus corroborating our findings. However, there is no report concerning its activity against S. flexneri until now [36-17]. The potent activity of a hydroethanolic extract of Desmoncus orthacanthos (HEDo) was observed only against $S$. flexneri (MIC $=25 \mu \mathrm{g} / \mathrm{ml}$ ). We were unable to make the comparison as there does not exist in the literature information on its in vitro antibacterial activity.

Moderate activity was demonstrated only against $S$. pyogenes $(\mathrm{MIC}=$ 
$100 \mu \mathrm{g} / \mathrm{ml}$ ) by HERa, but it was inactive against all other bacteria. This represents the first report of antibacterial activity of HERa against this strain, which is associated to a variety of infections, such as erysipelas, necrotizing fasciitis, biofilm formation and especially in bacteraemia cases [37]. In this context, this extract represents phytotherapeutic potential against $S$. pyogenes, however, further pharmacological, and phytochemical investigations are warranted.

Extracts that presented activity against $H$. pylori deserved to be highlighted, as this bacterium is regarded to be the main etiological agent of chronic gastritis, gastroduodenal ulcer, adenocarcinoma, and gastric lymphomas [38]. Among the extracts are the hydroethanolic extracts of the bark of HECr and HEBe, the leaves of D. ambrosioides (HEDa) and S. mombin (HESm).

HECr showed moderate activity against $H$. pylori with MIC $=100$ $\mu \mathrm{g} / \mathrm{ml}$, while HEBe, HEDa and HESm also present same moderate activity but at a higher MIC of $200 \mu \mathrm{g} / \mathrm{ml}$. There are no reports of anti-H. pylori activity for these extracts and therefore these plants may represent potential phytotherapeutic agents in the treatment of infections caused by $H$. pylori. Lima Neto et al. [39] reported that HECr showed activity against $S$. aureus, E. faecalis, E. coli and $P$. aeruginosa (MIC $=250--1000 \mu \mathrm{g} / \mathrm{ml}$ ), however, the same effect could not be demonstrated in our study.

Liu et al. [40] related that the essential oil of $C$. ambrosioides presents activity (MIC $=640 \mu \mathrm{g} / \mathrm{ml}$ ) against resistant strains of $H$. pylori, but at this concentration we considered this activity to be weak, based on the criteria that we employed.

In addition to the anti-H. pylori activity, HESm presented moderate activity against $E$. faecalis and $S$. aureus (MIC $=200$ and $400 \mu \mathrm{g} / \mathrm{ml}$, respectively) and weak activity against $S$. pyogenes (MIC $=800$

Table 3: Evaluation of in vitro antifungal activity of the hydroethanolic extracts of medicinal plants used for the treatment of infections

\begin{tabular}{|c|c|c|c|c|c|c|c|c|c|c|c|c|c|c|}
\hline \multirow[t]{4}{*}{ Species/Extract } & \multicolumn{14}{|c|}{${ }^{a}$ Minimum inhibitory concentration (MIC, $\mu \mathrm{g} / \mathrm{ml}$ ) } \\
\hline & \multirow{2}{*}{\multicolumn{6}{|c|}{ yeast-like fungi }} & \multicolumn{8}{|c|}{ Filamentous } \\
\hline & & & & & & & \multicolumn{4}{|c|}{ Aspergillus } & \multicolumn{4}{|c|}{ Dermatophytes } \\
\hline & Cal & Ca6 & $C p$ & Ct & $\mathrm{Cg}$ & Cn & $A f$ & An & $A p$ & At & $P v$ & $T m$ & $\operatorname{Tr}$ & $M g$ \\
\hline Aristolochia cymbifera Mart. \& Zucc. (bl)/HEAc & $\begin{array}{l}>80 \\
0\end{array}$ & $\begin{array}{l}>80 \\
0\end{array}$ & $\begin{array}{l}>80 \\
0\end{array}$ & $\begin{array}{l}>80 \\
0\end{array}$ & $\begin{array}{l}>80 \\
0\end{array}$ & $\begin{array}{l}>80 \\
0\end{array}$ & $\begin{array}{l}>80 \\
0\end{array}$ & 200 & $\begin{array}{l}>80 \\
0\end{array}$ & $\begin{array}{l}>80 \\
0\end{array}$ & $\begin{array}{l}>80 \\
0\end{array}$ & $\begin{array}{l}>80 \\
0\end{array}$ & $\begin{array}{l}>80 \\
0\end{array}$ & $\begin{array}{l}>80 \\
0\end{array}$ \\
\hline Phanera glabra (Jacq.) Vaz / HEPg & $\begin{array}{l}>80 \\
0\end{array}$ & $\begin{array}{l}>80 \\
0\end{array}$ & $\begin{array}{l}>80 \\
0\end{array}$ & $\begin{array}{l}>80 \\
0\end{array}$ & $\begin{array}{l}>80 \\
0\end{array}$ & $\begin{array}{l}>80 \\
0\end{array}$ & 200 & $\begin{array}{l}>80 \\
0\end{array}$ & $\begin{array}{l}>80 \\
0\end{array}$ & $\begin{array}{l}>80 \\
0\end{array}$ & $\begin{array}{l}>80 \\
0\end{array}$ & $\begin{array}{l}>80 \\
0\end{array}$ & $\begin{array}{l}>80 \\
0\end{array}$ & $\begin{array}{l}>80 \\
0\end{array}$ \\
\hline Bertholletia excelsa Bonpl. (b)/HEBe & 800 & $\begin{array}{l}>80 \\
0\end{array}$ & $\begin{array}{l}>80 \\
0\end{array}$ & 800 & 400 & 400 & 200 & $\begin{array}{l}>80 \\
0\end{array}$ & $\begin{array}{l}>80 \\
0\end{array}$ & 100 & $\begin{array}{l}>80 \\
0\end{array}$ & $\begin{array}{l}>80 \\
0\end{array}$ & $\begin{array}{l}>80 \\
0\end{array}$ & $\begin{array}{l}>80 \\
0\end{array}$ \\
\hline Brunfelsia uniflora (Pohl) D. Don (r)/HEBu & $\begin{array}{l}>80 \\
0\end{array}$ & $\begin{array}{l}>80 \\
0\end{array}$ & $\begin{array}{l}>80 \\
0\end{array}$ & $\begin{array}{l}>80 \\
0\end{array}$ & $\begin{array}{l}>80 \\
0\end{array}$ & $\begin{array}{l}>80 \\
0\end{array}$ & $\begin{array}{l}>80 \\
0\end{array}$ & $\begin{array}{l}>80 \\
0\end{array}$ & $\begin{array}{l}>80 \\
0\end{array}$ & $\begin{array}{l}>80 \\
0\end{array}$ & $\begin{array}{l}>80 \\
0\end{array}$ & $\begin{array}{l}>80 \\
0\end{array}$ & $\begin{array}{l}>80 \\
0\end{array}$ & $\begin{array}{l}>80 \\
0\end{array}$ \\
\hline Cariniana rubra Gardner ex Miers (b)/HECr & $\begin{array}{l}>80 \\
0\end{array}$ & $\begin{array}{l}>80 \\
0\end{array}$ & $\begin{array}{l}>80 \\
0\end{array}$ & $\begin{array}{l}>80 \\
0\end{array}$ & $\begin{array}{l}>80 \\
0\end{array}$ & $\begin{array}{l}>80 \\
0\end{array}$ & 200 & $\begin{array}{l}>80 \\
0\end{array}$ & $\begin{array}{l}>80 \\
0\end{array}$ & $\begin{array}{l}>80 \\
0\end{array}$ & $\begin{array}{l}>80 \\
0\end{array}$ & $\begin{array}{l}>80 \\
0\end{array}$ & $\begin{array}{l}>80 \\
0\end{array}$ & $\begin{array}{l}>80 \\
0\end{array}$ \\
\hline Cedrela odorata L. (b)/HECo & $\begin{array}{l}>80 \\
0 \\
\end{array}$ & $\begin{array}{l}>80 \\
0\end{array}$ & $\begin{array}{l}>80 \\
0\end{array}$ & $\begin{array}{l}>80 \\
0\end{array}$ & $\begin{array}{l}>80 \\
0 \\
\end{array}$ & $\begin{array}{l}>80 \\
0\end{array}$ & $\begin{array}{l}>80 \\
0 \\
\end{array}$ & $\begin{array}{l}>80 \\
0 \\
\end{array}$ & $\begin{array}{l}>80 \\
0 \\
\end{array}$ & $\begin{array}{l}>80 \\
0 \\
\end{array}$ & 800 & $\begin{array}{l}>80 \\
0 \\
\end{array}$ & 800 & 400 \\
\hline $\begin{array}{llll}\begin{array}{l}\text { Dysphania ambrosioides } \\
\text { Clemants/HEDa }\end{array} & \text { (L.) Mosyakin \& } \\
\end{array}$ & $\begin{array}{l}>80 \\
0\end{array}$ & $\begin{array}{l}>80 \\
0\end{array}$ & $\begin{array}{l}>80 \\
0\end{array}$ & $\begin{array}{l}>80 \\
0\end{array}$ & $\begin{array}{l}>80 \\
0\end{array}$ & $\begin{array}{l}>80 \\
0\end{array}$ & $\begin{array}{l}>80 \\
0\end{array}$ & $\begin{array}{l}>80 \\
0\end{array}$ & $\begin{array}{l}>80 \\
0\end{array}$ & $\begin{array}{l}>80 \\
0\end{array}$ & $\begin{array}{l}>80 \\
0\end{array}$ & $\begin{array}{l}>80 \\
0\end{array}$ & $\begin{array}{l}>80 \\
0\end{array}$ & $\begin{array}{l}>80 \\
0\end{array}$ \\
\hline Cordia nodosa Lam. (l)/HECn & $\begin{array}{l}>80 \\
0\end{array}$ & $\begin{array}{l}>80 \\
0\end{array}$ & $\begin{array}{l}>80 \\
0\end{array}$ & $\begin{array}{l}>80 \\
0\end{array}$ & $\begin{array}{l}>80 \\
0\end{array}$ & $\begin{array}{l}>80 \\
0\end{array}$ & $\begin{array}{l}>80 \\
0\end{array}$ & $\begin{array}{l}>80 \\
0\end{array}$ & $\begin{array}{l}>80 \\
0\end{array}$ & 800 & $\begin{array}{l}>80 \\
0\end{array}$ & $\begin{array}{l}>80 \\
0\end{array}$ & $\begin{array}{l}>80 \\
0\end{array}$ & $\begin{array}{l}>80 \\
0\end{array}$ \\
\hline Cymbopogon citratus (DC.) Stapfc (l)/HECcy & $\begin{array}{l}>80 \\
0\end{array}$ & $\begin{array}{l}>80 \\
0\end{array}$ & $\begin{array}{l}>80 \\
0\end{array}$ & $\begin{array}{l}>80 \\
0\end{array}$ & $\begin{array}{l}>80 \\
0\end{array}$ & $\begin{array}{l}>80 \\
0\end{array}$ & $\begin{array}{l}>80 \\
0\end{array}$ & $\begin{array}{l}>80 \\
0\end{array}$ & $\begin{array}{l}>80 \\
0\end{array}$ & $\begin{array}{l}>80 \\
0\end{array}$ & $\begin{array}{l}>80 \\
0\end{array}$ & $\begin{array}{l}>80 \\
0\end{array}$ & $\begin{array}{l}>80 \\
0\end{array}$ & $\begin{array}{l}>80 \\
0\end{array}$ \\
\hline Cyperus corymbosus Rottb. (rh)/HECc & $\begin{array}{l}>80 \\
0\end{array}$ & $\begin{array}{l}>80 \\
0\end{array}$ & $\begin{array}{l}>80 \\
0\end{array}$ & $\begin{array}{l}>80 \\
0\end{array}$ & $\begin{array}{l}>80 \\
0\end{array}$ & $\begin{array}{l}>80 \\
0\end{array}$ & $\begin{array}{l}>80 \\
0\end{array}$ & 800 & $\begin{array}{l}>80 \\
0\end{array}$ & $\begin{array}{l}>80 \\
0\end{array}$ & $\begin{array}{l}>80 \\
0\end{array}$ & $\begin{array}{l}>80 \\
0\end{array}$ & $\begin{array}{l}>80 \\
0\end{array}$ & $\begin{array}{l}>80 \\
0\end{array}$ \\
\hline Desmoncus orthacanthos Mart. (bl)/HEDo & $\begin{array}{l}>80 \\
0\end{array}$ & $\begin{array}{l}>80 \\
0\end{array}$ & $\begin{array}{l}>80 \\
0\end{array}$ & $\begin{array}{l}>80 \\
0\end{array}$ & $\begin{array}{l}>80 \\
0\end{array}$ & $\begin{array}{l}>80 \\
0\end{array}$ & $\begin{array}{l}>80 \\
0\end{array}$ & 400 & $\begin{array}{l}>80 \\
0 \\
\end{array}$ & $\begin{array}{l}>80 \\
0\end{array}$ & $\begin{array}{l}>80 \\
0\end{array}$ & $\begin{array}{l}>80 \\
0\end{array}$ & $\begin{array}{l}>80 \\
0\end{array}$ & $\begin{array}{l}>80 \\
0\end{array}$ \\
\hline $\begin{array}{l}\begin{array}{l}\text { Dichorisandra hexandra (Aubl.) } \\
\text { (l)/HEDh }\end{array} \\
\text { (l) }\end{array}$ & $\begin{array}{l}>80 \\
0\end{array}$ & $\begin{array}{l}>80 \\
0\end{array}$ & $\begin{array}{l}>80 \\
0\end{array}$ & $\begin{array}{l}>80 \\
0\end{array}$ & $\begin{array}{l}>80 \\
0\end{array}$ & $\begin{array}{l}>80 \\
0\end{array}$ & $\begin{array}{l}>80 \\
0\end{array}$ & $\begin{array}{l}>80 \\
0\end{array}$ & $\begin{array}{l}>80 \\
0\end{array}$ & $\begin{array}{l}>80 \\
0\end{array}$ & 800 & $\begin{array}{l}>80 \\
0\end{array}$ & $\begin{array}{l}>80 \\
0\end{array}$ & $\begin{array}{l}>80 \\
0\end{array}$ \\
\hline Digitaria insularis (L.) Fedde (l)/HEDi & $\begin{array}{l}>80 \\
0\end{array}$ & $\begin{array}{l}>80 \\
0\end{array}$ & $\begin{array}{l}>80 \\
0\end{array}$ & $\begin{array}{l}>80 \\
0\end{array}$ & $\begin{array}{l}>80 \\
0\end{array}$ & $\begin{array}{l}>80 \\
0\end{array}$ & $\begin{array}{l}>80 \\
0\end{array}$ & $\begin{array}{l}>80 \\
0\end{array}$ & $\begin{array}{l}>80 \\
0\end{array}$ & $\begin{array}{l}>80 \\
0\end{array}$ & $\begin{array}{l}>80 \\
0\end{array}$ & $\begin{array}{l}>80 \\
0\end{array}$ & $\begin{array}{l}>80 \\
0\end{array}$ & $\begin{array}{l}>80 \\
0\end{array}$ \\
\hline Eleusine indica (L.) Gaertn (l)/HEEi & $\begin{array}{l}>80 \\
0\end{array}$ & $\begin{array}{l}>80 \\
0\end{array}$ & $\begin{array}{l}>80 \\
0\end{array}$ & $\begin{array}{l}>80 \\
0\end{array}$ & $\begin{array}{l}>80 \\
0\end{array}$ & $\begin{array}{l}>80 \\
0\end{array}$ & $\begin{array}{l}>80 \\
0\end{array}$ & 800 & $\begin{array}{l}>80 \\
0\end{array}$ & 800 & $\begin{array}{l}>80 \\
0\end{array}$ & $\begin{array}{l}>80 \\
0\end{array}$ & $\begin{array}{l}>80 \\
0\end{array}$ & $\begin{array}{l}>80 \\
0\end{array}$ \\
\hline Gossypium hirsutum L. (1)/HEGi & $\begin{array}{l}>80 \\
0\end{array}$ & $\begin{array}{l}>80 \\
0\end{array}$ & $\begin{array}{l}>80 \\
0\end{array}$ & $\begin{array}{l}>80 \\
0\end{array}$ & $\begin{array}{l}>80 \\
0\end{array}$ & $\begin{array}{l}>80 \\
0\end{array}$ & $\begin{array}{l}>80 \\
0\end{array}$ & 800 & $\begin{array}{l}>80 \\
0\end{array}$ & $\begin{array}{l}>80 \\
0\end{array}$ & $\begin{array}{l}>80 \\
0\end{array}$ & $\begin{array}{l}>80 \\
0\end{array}$ & $\begin{array}{l}>80 \\
0\end{array}$ & $\begin{array}{l}>80 \\
0\end{array}$ \\
\hline Hedychium coronarium J. Koenig (rh)/HEHc & $\begin{array}{l}>80 \\
0\end{array}$ & $\begin{array}{l}>80 \\
0\end{array}$ & $\begin{array}{l}>80 \\
0\end{array}$ & $\begin{array}{l}>80 \\
0\end{array}$ & $\begin{array}{l}>80 \\
0\end{array}$ & $\begin{array}{l}>80 \\
0\end{array}$ & $\begin{array}{l}>80 \\
0\end{array}$ & $\begin{array}{l}>80 \\
0 \\
\end{array}$ & $\begin{array}{l}>80 \\
0 \\
\end{array}$ & $\begin{array}{l}>80 \\
0\end{array}$ & $\begin{array}{l}>80 \\
0\end{array}$ & $\begin{array}{l}>80 \\
0\end{array}$ & $\begin{array}{l}>80 \\
0\end{array}$ & $\begin{array}{l}>80 \\
0 \\
\end{array}$ \\
\hline Hevea microphylla Ule (b)/HEHm & $\begin{array}{l}>80 \\
0\end{array}$ & $\begin{array}{l}>80 \\
0\end{array}$ & $\begin{array}{l}>80 \\
0\end{array}$ & $\begin{array}{l}>80 \\
0\end{array}$ & $\begin{array}{l}>80 \\
0\end{array}$ & $\begin{array}{l}>80 \\
0\end{array}$ & $\begin{array}{l}>80 \\
0\end{array}$ & $\begin{array}{l}>80 \\
0\end{array}$ & $\begin{array}{l}>80 \\
0\end{array}$ & $\begin{array}{l}>80 \\
0\end{array}$ & $\begin{array}{l}>80 \\
0\end{array}$ & $\begin{array}{l}>80 \\
0\end{array}$ & $\begin{array}{l}>80 \\
0\end{array}$ & $\begin{array}{l}>80 \\
0\end{array}$ \\
\hline Jacaranda cuspidifolia Mart. (bl)/HEJc & $\begin{array}{l}>80 \\
0\end{array}$ & $\begin{array}{l}>80 \\
0\end{array}$ & $\begin{array}{l}>80 \\
0\end{array}$ & $\begin{array}{l}>80 \\
0\end{array}$ & $\begin{array}{l}>80 \\
0\end{array}$ & $\begin{array}{l}>80 \\
0\end{array}$ & $\begin{array}{l}>80 \\
0\end{array}$ & $\begin{array}{l}>80 \\
0\end{array}$ & $\begin{array}{l}>80 \\
0\end{array}$ & $\begin{array}{l}>80 \\
0\end{array}$ & $\begin{array}{l}>80 \\
0\end{array}$ & $\begin{array}{l}>80 \\
0\end{array}$ & $\begin{array}{l}>80 \\
0\end{array}$ & $\begin{array}{l}>80 \\
0\end{array}$ \\
\hline Manihot esculenta Crantz (l)/HEMt & $\begin{array}{l}>80 \\
0 \\
\end{array}$ & $\begin{array}{l}>80 \\
0 \\
\end{array}$ & $\begin{array}{l}>80 \\
0 \\
\end{array}$ & $\begin{array}{l}>80 \\
0 \\
\end{array}$ & $\begin{array}{l}>80 \\
0 \\
\end{array}$ & $\begin{array}{l}>80 \\
0\end{array}$ & $\begin{array}{l}>80 \\
0 \\
\end{array}$ & $\begin{array}{l}>80 \\
0 \\
\end{array}$ & $\begin{array}{l}>80 \\
0 \\
\end{array}$ & $\begin{array}{l}>80 \\
0 \\
\end{array}$ & $\begin{array}{l}>80 \\
0 \\
\end{array}$ & $\begin{array}{l}>80 \\
0 \\
\end{array}$ & $\begin{array}{l}>80 \\
0 \\
\end{array}$ & $\begin{array}{l}>80 \\
0 \\
\end{array}$ \\
\hline
\end{tabular}

$\mu \mathrm{g} / \mathrm{ml})$. Maduka et al. [41] showed that the ethanolic extracts of the leaves and bark of $S$. mombin showed activity against E. coli (inhibition halos of $20 \%$ for both extracts), K. pneumoniae and $P$. aeruginosa (inhibition halos of 40 and $20 \%$, respectively) and $S$. aureus (inhibition halos of $60 \%$ ). Regarding the latter strain, our results corroborate that of Maduka et al. [41]. In our work, HESm showed no activity against E. coli, P. aeruginosa and K. pneumoniae, which may be caused by the methods employed (solid medium compared to liquid medium) or even to seasonal variations (e. g. harvest location) [33].

\section{Antifungal activity}

The results of the effects of the extract on the fungal growth are displayed in table 3 . Out of the 26 tested extracts, 14 (53.8\%) showed activity against at least one fungal strain tested.

In this anti-fungal activity screening, HEBe was the most active compared to the hydroethanolic extract of A. cymbifera (HEAc), HEDo, HECr and HECo.

HEBe was the only extract that presented broad antifungal spectrum, with moderate activity against $A$. terreus (MIC $=100 \mu \mathrm{g} / \mathrm{ml}$ ), $A$ fumigatus (MIC $=200 \mu \mathrm{g} / \mathrm{ml}$ ), C. glabrata and C. neoformans (MIC = $400 \mu \mathrm{g} / \mathrm{ml}$ ), and weak activity against C. albicans and C. tropicalis (MIC $=800 \mu \mathrm{g} / \mathrm{ml}$ ). There is no report of HEBe antifungal activity until now, though Martins et al. [42] demonstrated that the pure oil ( $\mathrm{v}=500$ $1500 \mu \mathrm{l}$ ) obtained from the nuts of $B$. excelsa was active against toxicogenic strains of A. parasiticus, an effect that was not observed for HEBe in this study. However, it is worth noting that the concentration tested by Martins et al. [42], if classified according to Holetz et al. [17], would be considered inactive. 


\begin{tabular}{|c|c|c|c|c|c|c|c|c|c|c|c|c|c|c|}
\hline Maytenus ilicifolia Mart. ex Reissek (b) HEMi & $\begin{array}{l}>80 \\
0\end{array}$ & $\begin{array}{l}>80 \\
0\end{array}$ & $\begin{array}{l}>80 \\
0\end{array}$ & $\begin{array}{l}>80 \\
0\end{array}$ & $\begin{array}{l}>80 \\
0\end{array}$ & $\begin{array}{l}>80 \\
0\end{array}$ & $\begin{array}{l}>80 \\
0\end{array}$ & $\begin{array}{l}>80 \\
0\end{array}$ & $\begin{array}{l}>80 \\
0\end{array}$ & $\begin{array}{l}>80 \\
0\end{array}$ & $\begin{array}{l}>80 \\
0\end{array}$ & $\begin{array}{l}>80 \\
0\end{array}$ & $\begin{array}{l}>80 \\
0\end{array}$ & $\begin{array}{l}>80 \\
0\end{array}$ \\
\hline $\begin{array}{l}\text { Parodiolyra micrantha (Kunth) Davidse \& } \\
\text { Zuloaga (l)/HEPm }\end{array}$ & $\begin{array}{l}>80 \\
0\end{array}$ & $\begin{array}{l}>80 \\
0\end{array}$ & $\begin{array}{l}>80 \\
0\end{array}$ & $\begin{array}{l}>80 \\
0\end{array}$ & $\begin{array}{l}>80 \\
0\end{array}$ & $\begin{array}{l}>80 \\
0\end{array}$ & $\begin{array}{l}>80 \\
0\end{array}$ & $\begin{array}{l}>80 \\
0\end{array}$ & $\begin{array}{l}>80 \\
0\end{array}$ & $\begin{array}{l}>80 \\
0\end{array}$ & $\begin{array}{l}>80 \\
0\end{array}$ & $\begin{array}{l}>80 \\
0\end{array}$ & $\begin{array}{l}>80 \\
0\end{array}$ & $\begin{array}{l}>80 \\
0\end{array}$ \\
\hline Philodendron acutatum Schott (wp) HEPa & $\begin{array}{l}>80 \\
0 \\
\end{array}$ & $\begin{array}{l}>80 \\
0\end{array}$ & $\begin{array}{l}>80 \\
0\end{array}$ & $\begin{array}{l}>80 \\
0\end{array}$ & $\begin{array}{l}>80 \\
0\end{array}$ & $\begin{array}{l}>80 \\
0\end{array}$ & 800 & $\begin{array}{l}>80 \\
0\end{array}$ & $\begin{array}{l}>80 \\
0\end{array}$ & $\begin{array}{l}>80 \\
0\end{array}$ & 800 & $\begin{array}{l}>80 \\
0\end{array}$ & $\begin{array}{l}>80 \\
0\end{array}$ & 800 \\
\hline Renealmia alpinia (Rottb.) Maas (rh)/HERa & $\begin{array}{l}>80 \\
0\end{array}$ & $\begin{array}{l}>80 \\
0\end{array}$ & $\begin{array}{l}>80 \\
0\end{array}$ & $\begin{array}{l}>80 \\
0\end{array}$ & $\begin{array}{l}>80 \\
0\end{array}$ & $\begin{array}{l}>80 \\
0\end{array}$ & $\begin{array}{l}>80 \\
0 \\
\end{array}$ & $\begin{array}{l}>80 \\
0\end{array}$ & $\begin{array}{l}>80 \\
0\end{array}$ & $\begin{array}{l}>80 \\
0\end{array}$ & $\begin{array}{l}>80 \\
0\end{array}$ & $\begin{array}{l}>80 \\
0\end{array}$ & $\begin{array}{l}>80 \\
0\end{array}$ & $\begin{array}{l}>80 \\
0\end{array}$ \\
\hline Smilax brasiliensis Spreng. (bl)/HESb & $\begin{array}{l}>80 \\
0\end{array}$ & $\begin{array}{l}>80 \\
0\end{array}$ & $\begin{array}{l}>80 \\
0\end{array}$ & $\begin{array}{l}>80 \\
0\end{array}$ & $\begin{array}{l}>80 \\
0\end{array}$ & $\begin{array}{l}>80 \\
0\end{array}$ & 800 & $\begin{array}{l}>80 \\
0\end{array}$ & $\begin{array}{l}>80 \\
0\end{array}$ & $\begin{array}{l}>80 \\
0\end{array}$ & $\begin{array}{l}>80 \\
0\end{array}$ & $\begin{array}{l}>80 \\
0\end{array}$ & $\begin{array}{l}>80 \\
0\end{array}$ & $\begin{array}{l}>80 \\
0\end{array}$ \\
\hline Spondias mombin L. (l)/HESm & $\begin{array}{l}>80 \\
0\end{array}$ & $\begin{array}{l}>80 \\
0\end{array}$ & $\begin{array}{l}>80 \\
0\end{array}$ & $\begin{array}{l}>80 \\
0\end{array}$ & $\begin{array}{l}>80 \\
0\end{array}$ & $\begin{array}{l}>80 \\
0\end{array}$ & 800 & $\begin{array}{l}>80 \\
0\end{array}$ & $\begin{array}{l}>80 \\
0\end{array}$ & $\begin{array}{l}>80 \\
0\end{array}$ & $\begin{array}{l}>80 \\
0\end{array}$ & $\begin{array}{l}>80 \\
0\end{array}$ & 800 & 800 \\
\hline Trema micrantha (L.) Blume (bl)/HETm & $\begin{array}{l}>80 \\
0\end{array}$ & $\begin{array}{l}>80 \\
0\end{array}$ & $\begin{array}{l}>80 \\
0\end{array}$ & $\begin{array}{l}>80 \\
0\end{array}$ & $\begin{array}{l}>80 \\
0\end{array}$ & $\begin{array}{l}>80 \\
0\end{array}$ & $\begin{array}{l}>80 \\
0\end{array}$ & $\begin{array}{l}>80 \\
0\end{array}$ & $\begin{array}{l}>80 \\
0\end{array}$ & $\begin{array}{l}>80 \\
0\end{array}$ & $\begin{array}{l}>80 \\
0\end{array}$ & $\begin{array}{l}>80 \\
0\end{array}$ & $\begin{array}{l}>80 \\
0\end{array}$ & $\begin{array}{l}>80 \\
0\end{array}$ \\
\hline \multicolumn{15}{|l|}{ Standard drug } \\
\hline Amphotericin & $\begin{array}{l}0.12 \\
5 \\
\end{array}$ & $\begin{array}{l}0.2 \\
5 \\
\end{array}$ & 0.5 & $\begin{array}{l}0.2 \\
5 \\
\end{array}$ & $\begin{array}{l}0.12 \\
5\end{array}$ & $\begin{array}{l}0.2 \\
5 \\
\end{array}$ & $\begin{array}{l}0.3 \\
9 \\
\end{array}$ & $\begin{array}{l}0.3 \\
9 \\
\end{array}$ & $\begin{array}{l}0.3 \\
9 \\
\end{array}$ & $\begin{array}{l}0.3 \\
9 \\
\end{array}$ & $\begin{array}{l}0.3 \\
9 \\
\end{array}$ & $\begin{array}{l}0.7 \\
8 \\
\end{array}$ & $\begin{array}{l}0.7 \\
8 \\
\end{array}$ & $\begin{array}{l}0.7 \\
8 \\
\end{array}$ \\
\hline
\end{tabular}

aObtained by broth microdilution, (b): bark; (bl): branches and leaves; (l) leaves; (rh): rhizome; (r): root (sb): stem bark; (wp): whole plant; Ca1: Candida albicans, Ca6: Candida albicans fluconazole-resistente, Cp: Candida parapsilosis, Ct: Candida tropicalis, Cn: Cryptococcus neoformans, Cg: Candida glabrata, Af: Aspergillus fumigatus, An: Aspergillus niger,Ap: Aspergillus parasiticus, At: Aspergillus terreus, Pv: Penicillium verrucosum, Tm: Trichophyton mentagrophytes, Tr: Trichophyton rubrum, Mg: Microsporum gypseum, Results expressed as mean of three independent assays.

However, this above-mentioned study differs from ours in the chemical constituents of the plant (essential oil compared to the hydroethanolic extract), the part of the plant that was tested (nuts against the bark) and the methodology applied (disc diffusion against broth microdilution) [43].

The yeast-like fungi of the Candida genus are the most common hospital infectious agents. C. glabrata has reduced sensitivity to most conventional antifungal drugs and is associated with skin, mucosal and systemic infections [44]. The infections caused by $C$. neoformans occur in in-patients who are at advanced state of human immunodeficiency virus (HIV) infection.

It is estimated that one million people are infected with cryptococcal meningitis in the world [45]. Finally, there are the filamentous fungi that are highly lethal, among which is the genus Aspergillus, known to include opportunistic species that are frequently encountered in intensive care units and surgical centres, responsible for the cause of endocarditis and pulmonary infections [46]. Based on our results, HEBe may be a potential candidate in the treatment of fungal illnesses, although further pharmacological and phytochemical studies for the clarification of its mechanism of action and identification of the compounds responsible for this effect.

HEAc and HEDo and HEPg and HECr exhibited a narrow spectrum of action and moderate antifungal activity only against $A$. niger (MIC = 200 and $400 \mu \mathrm{g} / \mathrm{ml}$ ) and $A$. fumigatus (MIC $=200 \mu \mathrm{g} / \mathrm{ml}$ ), respectively. It was not possible to do a comparison for these extracts as there are no reports of their antifungal activities.

Contrary to the reported antifungal activity of the methanolic extract of $A$. cymbifera against $C$. albicans $\left(\mathrm{IC}_{50}=49.66 \mu \mathrm{g} / \mathrm{ml}\right.$ ) by Tempone et al. [47], HEAc had no detected activity against this strain in the present study. This inactivity may be related to seasonality (harvest time and location) or even to the genetic composition of the plant (variety) which also directly affects the levels of compounds responsible for the antifungal activity [33].

A. fumigatus and A. niger are two of the most common causes of bronchopulmonary aspergillosis, which is currently one of the infections with the highest mortality rates, with the rate as high as 50-90\%, even after the administration of antifungal therapy, in immunocompromised patients [48, 49]. Therefore, these extracts may serve as alternatives in the treatment of opportunistic infections, especially in cases of nosocomial infections.

Among the tested extracts, only HECo showed moderate activity against the dermatophyte $M$. gypseum $(\mathrm{MIC}=400 \mu \mathrm{g} / \mathrm{ml}$ ) and weak activity against $P$. verrucosum and T. rubrum (MIC $=800 \mu \mathrm{g} / \mathrm{ml}$ ). The only report in literature about antifungal activity of Cedrela odorata by Idu et al. [50] reported that the ethanolic and chloroformic extracts of the leaves and bark essential oil of $C$. odorata showed activity against $C$. albicans (MIC $=50 \mathrm{mg} / \mathrm{ml}$ ), $P$. notatum and $M u c o r$ mucedo (MIC = $100 \mathrm{mg} / \mathrm{ml}$, for both), however, the tested concentrations were very high, and, for this reason, we considered it as inactive according to the criteria used in the present study.

Dermatophytoses are the most frequent fungal infections in the world, affecting various age-groups and causing a reduction on the patient's quality of life, not to mention the financial aspect of the medical treatments [51]. M. gypseum is responsible for $20 \%$ of the dermatophytic infections and the main problems concerning their eradication are the increase in the resistant strains, shortages in a variety of the antifungal classes and toxicity associated with the treatment [52]. Therefore, HECo deserves further experimental evaluation with the intent of developing it as a prototype phytotherapeutic option to dermatophytosis treatment. This should include steps to concentrate its pharmacological activity and or isolation of phytoconstituents responsible for its anti-fungal action.

\section{Antioxidant activity and their correlations to the polyphenol contents}

Kintzios et al. [53] stressed the importance of identifying agents involved in sequestering ROS and prevention of their deleterious actions on cells and tissues. Among these substances, three metabolic classes are prominent, namely-phenols, flavonoids and coumarins, which contain substances known to possess antioxidant, antiradical, and antimicrobial activities [54].

Table 4: Evaluation of the in vitro antioxidant activity and the concentrations of total phenolic compounds, total flavonoids, and coumarins of the hydroethanolic extracts of medicinal plants used for the treatment of infections

\begin{tabular}{|c|c|c|c|c|c|c|}
\hline \multirow[t]{2}{*}{ Species/extract } & DPPH & FRAP & NO & \multirow{2}{*}{$\begin{array}{l}\begin{array}{l}\text { Total } \\
\text { phenols }\end{array} \\
\text { mg } \\
\text { TAE/g } \pm \text { SD }\end{array}$} & Flavonoids & Coumarins \\
\hline & \multicolumn{3}{|c|}{$\mathrm{IC}_{50} \pm \mathrm{SD}, \mu \mathrm{g} / \mathrm{ml}$} & & $\begin{array}{l}\mathrm{mg} \\
\mathrm{RE} / \mathrm{g} \pm \mathrm{SD}\end{array}$ & $\begin{array}{l}\mathrm{mg} \\
\mathrm{CE} / \mathrm{g} \pm \mathrm{SD}\end{array}$ \\
\hline Aristolochia cymbifera Mart. and Zucc. (bl)/HEAc & $96.91 \pm 0.72$ & $>800$ & $\begin{array}{l}>80 \\
0\end{array}$ & $3.67 \pm 0.09$ & $1.21 \pm 0.00$ & $1.36 \pm 0.01$ \\
\hline Phanera glabra (Jacq.) Vaz / HEPg & $4.67 \pm 0.21$ & $60.76 \pm 1.52$ & $\begin{array}{l}>80 \\
0\end{array}$ & $5.61 \pm 0.01$ & $1.04 \pm 0.00$ & $1.22 \pm 0.01$ \\
\hline
\end{tabular}




\begin{tabular}{|c|c|c|c|c|c|c|}
\hline Bertholletia excelsa Bonpl. (b)/HEBe & $0.39 \pm 0.08$ & $65.00 \pm 8.67$ & $\begin{array}{l}>80 \\
0\end{array}$ & $10.91 \pm 0.39$ & $0.82 \pm 0.00$ & $1.38 \pm 0.01$ \\
\hline Brunfelsia uniflora (Pohl) D. Don (r)/HEBu & $\begin{array}{l}254.66 \pm 2.8 \\
9\end{array}$ & $>800$ & $\begin{array}{l}>80 \\
0\end{array}$ & $0.63 \pm 0.00$ & $0.61 \pm 0.02$ & $1.09 \pm 0.02$ \\
\hline Cariniana rubra Gardner ex Miers (b)/HECr & $0.44 \pm 0.16$ & $64.00 \pm 4.43$ & $\begin{array}{l}>80 \\
0\end{array}$ & $5.05 \pm 0.03$ & $0.94 \pm 0.02$ & $1.12 \pm 0.00$ \\
\hline Cedrela odorata L. (b)/HECo & $0.56 \pm 0.08$ & $56.37 \pm 0.75$ & $\begin{array}{l}>80 \\
0\end{array}$ & $8.98 \pm 0.37$ & $0.99 \pm 0.02$ & $1.17 \pm 0.01$ \\
\hline Dysphania ambrosioides (L.) Mosyakin \& Clemants/HEDa & $0.64 \pm 0.04$ & $>800$ & $\begin{array}{l}>80 \\
0\end{array}$ & $0.23 \pm 0.03$ & $1.33 \pm 0.02$ & $1.20 \pm 0.00$ \\
\hline Cordia nodosa Lam. (I)/HECn & $74.00 \pm 0.29$ & $480.00 \pm 8.66$ & $\begin{array}{l}>80 \\
0\end{array}$ & $4.66 \pm 0.02$ & $1.59 \pm 0.02$ & $1.61 \pm 0.00$ \\
\hline Cymbopogon citratus (DC.) Stapf (I)/HECc & $44.29 \pm 0.71$ & $>800$ & $\begin{array}{l}>80 \\
0\end{array}$ & $2.36 \pm 0.04$ & $1.04 \pm 0.00$ & $1.93 \pm 0.01$ \\
\hline Cyperus corymbosus Rottb. (rh)/HECcy & $\begin{array}{l}117.08 \pm 0.7 \\
2\end{array}$ & $>800$ & $\begin{array}{l}>80 \\
0\end{array}$ & $0.74 \pm 0.04$ & $0.21 \pm 0.00$ & $0.91 \pm 0.00$ \\
\hline Desmoncus orthacanthos Mart. (bl)/HEDo & $\begin{array}{l}118.08 \pm 1.8 \\
8\end{array}$ & $>800$ & $\begin{array}{l}>80 \\
0\end{array}$ & $1.90 \pm 0.05$ & $1.66 \pm 0.02$ & $1.27 \pm 0.01$ \\
\hline Dichorisandra hexandra (Aubl.) C. B. Clarke (l)/HEDh & $\begin{array}{l}164.66 \pm 2.3 \\
1\end{array}$ & $>800$ & $\begin{array}{l}>80 \\
0\end{array}$ & $0.63 \pm 0.03$ & $1.49 \pm 0.00$ & $1.32 \pm 0.00$ \\
\hline Digitaria insularis (L.) Fedde (I)/HEDi & $\begin{array}{l}117.25 \pm 3.1 \\
8\end{array}$ & $>800$ & $\begin{array}{l}>80 \\
0\end{array}$ & $1.99 \pm 0.09$ & $1.06 \pm 0.03$ & $1.29 \pm 0.00$ \\
\hline Eleusine indica (L.) Gaertn(l)/HEEi & $7.76 \pm 0.21$ & $>800$ & $\begin{array}{l}>80 \\
0\end{array}$ & $0.31 \pm 0.01$ & $0.73 \pm 0.00$ & $0.93 \pm 0.00$ \\
\hline Gossypium hirsutum L. (1)/HEGi & $13.06 \pm 1.25$ & $>800$ & $\begin{array}{l}>80 \\
0\end{array}$ & $3.25 \pm 0.04$ & $2.26 \pm 0.02$ & $1.65 \pm 0.00$ \\
\hline Hedychium coronarium J. Koenig (rh)/HEHc & $\begin{array}{l}478.66 \pm 2.3 \\
1\end{array}$ & $>800$ & $\begin{array}{l}>80 \\
0\end{array}$ & $0.09 \pm 0.02$ & $0.68 \pm 0.02$ & $0.99 \pm 0.00$ \\
\hline Hevea microphylla Ule (b)/HEHm & $0.49 \pm 0.13$ & $255.00 \pm 2.02$ & $\begin{array}{l}>80 \\
0\end{array}$ & $4.50 \pm 0.03$ & $0.66 \pm 0.01$ & $1.26 \pm 0.00$ \\
\hline Jacaranda cuspidifolia Mart. (bl)/HEJc & $50.28 \pm 2.23$ & $>800$ & $\begin{array}{l}>80 \\
0\end{array}$ & $5.58 \pm 0.06$ & $0.42 \pm 0.00$ & $1.65 \pm 0.01$ \\
\hline Manihot esculenta Crantz (I)/HEMt & $33.37 \pm 0.87$ & $>800$ & $\begin{array}{l}>80 \\
0\end{array}$ & $3.01 \pm 0.06$ & $2.21 \pm 0.00$ & $1.45 \pm 0.00$ \\
\hline Maytenus ilicifolia Mart. ex Reissek (b) HEMi & $50.93 \pm 0.58$ & $441.00 \pm 0.12$ & $\begin{array}{l}>80 \\
0\end{array}$ & $4.0 \pm 0.023$ & $0.32 \pm 0.00$ & $0.99 \pm 0.00$ \\
\hline $\begin{array}{lllll}\begin{array}{l}\text { Parodiolyra micrantha } \\
\text { (1)/HEPm }\end{array} & \text { Kunth) Davidse \& Zuloaga } \\
\end{array}$ & $59.83 \pm 0.29$ & $>800$ & $\begin{array}{l}>80 \\
0\end{array}$ & $2.26 \pm 0.03$ & $0.54 \pm 0.00$ & $1.27 \pm 0.00$ \\
\hline Philodendron acutatum Schott (wp) HEPa & $13.51 \pm 0.36$ & $346.00 \pm 8.00$ & $\begin{array}{l}>80 \\
0\end{array}$ & $6.02 \pm 0.01$ & $4.40 \pm 0.02$ & $1.18 \pm 0.00$ \\
\hline Renealmia alpinia (Rottb.) Maas (rh)/HERa & $\begin{array}{l}107.25 \pm 0.0 \\
2\end{array}$ & $>800$ & $\begin{array}{l}>80 \\
0 \\
\end{array}$ & $1.51 \pm 0.02$ & $1.21 \pm 0.01$ & $1.08 \pm 0.00$ \\
\hline Smilax brasiliensis Spreng. (bl)/HESb & $\begin{array}{l}171.83 \pm 6.9 \\
3\end{array}$ & $>800$ & $\begin{array}{l}>80 \\
0 \\
\end{array}$ & $1.47 \pm 0.09$ & $0.32 \pm 0.00$ & $1.14 \pm 0.00$ \\
\hline Spondias mombin L. (l)/HESm & $0.47 \pm 0.01$ & $130.88 \pm 0.88$ & $\begin{array}{l}>80 \\
0 \\
\end{array}$ & $5.31 \pm 0.01$ & $0.59 \pm 0.00$ & $1.24 \pm 0.00$ \\
\hline Trema micrantha (L.) Blume (bl)/HETm & $\begin{array}{l}104.33 \pm 0.2 \\
9\end{array}$ & $>800$ & $\begin{array}{l}>80 \\
0 \\
\end{array}$ & $2.76 \pm 0.01$ & $0.68 \pm 0.00$ & $1.19 \pm 0.00$ \\
\hline \multicolumn{7}{|l|}{ Standart drugs } \\
\hline Ascorbic ácid & $1.9 \pm 0.01$ & $1.68 \pm 0.02$ & & & & \\
\hline Quercetin & \multicolumn{6}{|l|}{$3.12 \pm 0.05$} \\
\hline
\end{tabular}

Results expressed as $\mathrm{IC}_{50} \pm \mathrm{SD}$ for the antioxidant activity, for the quantification of polyphenols in mg of tannic acid per gramm of sample (mg TAE/g) for total phenolic compounds; $\mathrm{mg}$ of rutine per gramm of sample (mg RE/g) for total flavonoids; $\mathrm{mg}$ of coumarin per gramm of sample (mg CE/g) for coumarins. (b): bark; (bl): branches and leaves; (l) leaves; (rh): rhizome; (r): root (sb): stern bark; (wp): whole plant; quercetin. The assays were carried out in triplicate.

The methods used for estimation of the total antioxidant capacities were selected based on their simplicity, low cost, and reproducibility and since we evaluated the antioxidant potentials of the different plant's extracts since there is no single, widelyacceptable assay method applicable to a reasonable variety of compounds in plasma and plant matrices. Although, in vitro methods used in assessing radical scavenging activity are artificial radicals and do not reproduce in vivo situation, they are however, useful in the evaluation of the antioxidant activity in a rapid, easy, and inexpensive way. Besides, it is important to note that, a valid in vitro assay is an invaluable tool for clinical studies if it is combined with bioavailability data and valid oxidative stress biomarker assays [55, 56].

In this case, we employed the three commonly utilized antioxidant assays, namely DPPH, FRAP and NO scavenging assays to verify the antioxidant potential of each extracts. Where considered active in these models only the extracts whose values of inhibition/capture of ROS allowed for the calculation of $\mathrm{IC}_{50} \pm \mathrm{SD}$.

Table 4 displays the results of the antioxidant activity evaluation in vitro, as well as the concentrations of certain classes of polyphenols on the hydroethanolic extracts.

For further discussion of the antioxidant results, we selected, in the case of DPPH, only extracts with $\mathrm{IC}_{50}$ lower than the standard antioxidant, ascorbic acid, while in the case of FRAP, we discussed only extracts with $\mathrm{IC}_{50}$ equal or less than $100 \mu \mathrm{g} / \mathrm{ml}$.

It was noted that all 26 extracts exhibited, to a lesser or greater extent, the capacity to reduce DPPH radical, whereas, in the FRAP assay, only 9 extracts were capable of reducing $\mathrm{Fe}^{+3}$. None of the tested extracts presented detectable activity against NO, at the 
tested concentrations. However, quercetin, the standard drug for this assay, presented intense antioxidant activity with $\mathrm{IC}_{50}=$ $3.12 \pm 0.05 \mu \mathrm{g} / \mathrm{ml}$ in all the in vitro antioxidant models tested.

The content of total phenols in the hydroethanolic extract varied between $0.09-10.91 \mathrm{mg} \mathrm{TAE} / \mathrm{g}$, the highest content being in the HEBe $(10.91 \pm 0.08 \mathrm{mg} \mathrm{TAE} / \mathrm{g})$, HECo $(8.98 \pm 0.08 \mathrm{mg} \mathrm{TAE} / \mathrm{g}$ ) and HEPa $(6.02 \pm 0.01 \mathrm{mg} \mathrm{TAE} / \mathrm{g})$, while the lowest were present in HEHc $(0.09 \pm 0.02 \mathrm{mg} \mathrm{TAE} / \mathrm{g}), \mathrm{HEDa}(0.23 \pm 0.37 \mathrm{mg} \mathrm{TAE} / \mathrm{g})$ and HEEi $(0.31 \pm 0.01 \mathrm{mg} \mathrm{TAE} / \mathrm{g})$.

Flavonoid contents varied between 0.32-4.40 mg RE/g, the highest contents being in HEPa $(4.40 \pm 0.02 \mathrm{mg} \mathrm{RE} / \mathrm{g})$, HEGh $(2.26 \pm 0.02 \mathrm{mg}$ $\mathrm{RE} / \mathrm{g})$, HEMe $(2.21 \pm 0.00 \mathrm{mg} \mathrm{RE} / \mathrm{g})$ and HEDo $(1.66 \pm 0.02 \mathrm{mg} \mathrm{RE} / \mathrm{g})$, while the lowest were present in HECcy $(0.21 \pm 0.00 \mathrm{mg} \mathrm{RE} / \mathrm{g}), \mathrm{HESb}$ $(0.32 \pm 0.00 \mathrm{mg} \mathrm{RE} / \mathrm{g})$, HEMi $(0.32 \pm 0.00 \mathrm{mg} \mathrm{RE} / \mathrm{g})$ and $\mathrm{HEPm}$ $(0.54 \pm 0.00 \mathrm{mg} \mathrm{RE} / \mathrm{g})$.

As for the coumarin contents, the variation was between 0.91-1.93 $\mathrm{mg} \mathrm{EC} / \mathrm{g}$, the highest contents being in HECci $(1.93 \pm 0.01 \mathrm{mg} \mathrm{EC} / \mathrm{g})$, HEGh $(1.65 \pm 0.00 \mathrm{mg} \mathrm{EC} / \mathrm{g})$ and HECn $(1.61 \pm 0.00 \mathrm{mg}$ EC/g) while the lowest concentration were encountered in HECcy $(0.91 \pm 0.00 \mathrm{mg}$ $\mathrm{EC} / \mathrm{g})$, HEEi $(0.93 \pm 0.00 \mathrm{mg} \mathrm{EC} / \mathrm{g}), \mathrm{HEHc}$ and HEMi $(0.99 \pm 0.00 \mathrm{mg}$ $\mathrm{EC} / \mathrm{g})$.

The outstanding free radicals scavenging and antioxidant activities of the following extracts are notable: HEBe $\left(\mathrm{IC}_{50}=0.39 \pm 0.08\right.$ and $65.00 \pm 8.67 \mu \mathrm{g} / \mathrm{ml}), \operatorname{HECr}\left(\mathrm{IC}_{50}=0.44 \pm 0.16\right.$ and $\left.64.00 \pm 4.43 \mu \mathrm{g} / \mathrm{ml}\right)$ and HECo $\left(\mathrm{IC}_{50}=0.56 \pm 0.08\right.$ and $\left.56.37 \pm 0.75 \mu \mathrm{g} / \mathrm{ml}\right)$ for the DPPH and FRAP antioxidant models, respectively.

HESm $\left(\mathrm{IC}_{50}=0.47 \pm 0.01 \mu \mathrm{g} / \mathrm{ml}\right), \mathrm{HEHm}\left(\mathrm{IC}_{50}=0.49 \pm 0.13 \mu \mathrm{g} / \mathrm{ml}\right)$ and HECa ( $\mathrm{IC}_{50}=0.64 \pm 0.04 \mu \mathrm{g} / \mathrm{ml}$ ) exhibited activity only in the DPPH, whereas HEPg $\left(\mathrm{IC}_{50}=60.76 \pm 1.52 \mu \mathrm{g} / \mathrm{ml}\right)$ was active only in the FRAP.

It is worth mentioning that HEBe, HECr, HECo, HEHSm, HEHm and HEDa presented IC $\mathrm{I}_{50}$ values lower than that of the standard compound ascorbic acid $\left(\mathrm{IC}_{50}=1.90 \pm 0.01 \mu \mathrm{g} / \mathrm{ml}\right)$ in the DPPH model, while in the FRAP assay, HEBe, HECr, HECo and HEPg displayed $\mathrm{IC}_{50}$ greater than the standard drug $\left(\mathrm{IC}_{50}=1.68 \pm 0.02 \mu \mathrm{g} / \mathrm{mll}\right)$

John and Shahidi reported antioxidant activity for the methanolic ethanolic and acetone fractions of $B$. excelsa nuts in DPPH assay, however, with values of $\mathrm{IC}_{50} 1000$ times larger than those of HEBe [57]. The same authors showed that soluble and insoluble phenolic extracts of the kernel, nut, and shell, reduce ferric ion (0.21-59.20 $\mu \mathrm{mol}$ ascorbic acid eq/g), with activity equivalent to that obtained for HEBe $\left(\mathrm{IC}_{50}=35.22 \mu\right.$ moles ascorbic acid eq $\left./ \mathrm{ml}\right)$, indicating that the extracts of $B$. excelsa have antioxidant capacity in both models, being more active in the DPPH assay. In this screening, HEBe presented the highest contents of total phenolic compounds. Buratto et al. $[57,58]$ reported that the antioxidant activity of the nuts of $B$. excelsa is related to the presence of these compounds, suggesting that the antioxidant activity of HEBe may be due to the presence of this metabolic class.

The DPPH scavenging activity of HECr was close to that of HEBe. Lima et al. [59], reported radical scavenging activity in DPPH assay for the ethanolic extract of $C$. rubra, but at concentrations 3 times higher than the ones obtained in this study. These authors described the presence of phenolic compounds ( $\beta$-sitosterol, stigmasterol, amyrin and arjunolic acid) demonstrably antioxidant in the methanolic extract of C. rubra. This is the first report on the antioxidant activity of HECr using FRAP assay. These results indicate that phenolic compounds present in polar extracts of the bark of $C$. rubra, may be responsible, at least in part, for the antioxidant activity of the plant.

The DPPH scavenging activity of HECo was observed and it also yielded the lowest FRAP value. Lima [60] showed that the methanolic bark extract of $C$. odorata possessed antioxidant capacity in both models, but with about 60 and 20 times less active than HECo in the DPPH and FRAP assays, respectively. Rashed [61] also verified that the methanolic extract as well as the fractions of this plant as possessing DPPH scavenging activities, however, at higher concentrations ( $\mathrm{IC}_{50}=1 \mathrm{mg} / \mathrm{ml}$ ). Giordani et al. [62] described that HECo presents among its constituents, gallic acid and gallocatechin, and attributed the antioxidant activity of the extract to their presence. The higher antioxidant activity observed for HECo in this study compared to the literature may be due to the differences in the preparation techniques, which may result in variation in the content and type of phenolic compounds present in it.

HESm showed antioxidant activity only on DPPH assay. Akinmoladun et al. demonstrated that the methanolic extract of the leaves of $S$. mombin and its fractions presented antioxidant activity against DPPH radical but at concentrations 20 times higher than those of HESm. Akinmoladun et al. and Igwe et al. [63-65] stated that the methanolic extract of the leaves of S. mombin is rich in flavonoid and phenolic contents, metabolic classes known to be rich in antioxidant compounds also present in HESm.

HEHm presented antioxidant activity on DPPH assay, this being the first report of this activity for $H$. microphylla, Fernandes [66], demonstrated that the methanolic extract of the endosperm of Hevea sp. is rich in phenols also present in HEHm (apart from flavonoids and coumarins), which together could be responsible for the antioxidant effect of HEHm.

As with HEHm, HECa showed antioxidant activity on DPPH assay. Barros et al. [67] reported that the methanolic extract and the infusion inflorescences and upper leaves of $D$. ambrosioides capture the DPPH radical, but with $\mathrm{IC}_{50}$ values $(0.62$ and $0.49 \mathrm{mg} / \mathrm{ml}$, respectively) around 1000 times larger than that of HEDa. As for FRAP, the same authors report that both extracts were active, but at concentrations nearly 1000 times higher than those used in the present study with HEDa. In addition to the phenolic compounds found by Barros et al. [67], HEDa also presented flavonoids and coumarins, possibly related to the extract's antioxidant activity.

HEPg showed antioxidant activity only in FRAP assay, this being the first report of the activity for P. glabra, though there have been descriptions of antioxidant activity for some species belonging to this same genus, and particularly ascribed to the presence of phenolic compounds [68].

None of the hydroethanolic extracts tested yielded $\mathrm{IC}_{50}$ in the NO assay, although ten of the extracts inhibited the formation of this gas at percentages ranging from $10-33 \%$.

All the tested hydroethanolic extracts contained, to some extent, total phenols, flavonoids and coumarins. Since none of the extracts presented substantial effect in the NO assay, thus, the correlation studies between antioxidant activity and presence of a determined metabolic class only involved the extracts that were active in DPPH and FRAP assays.

As seen in table 5 and fig. 1 , there is a moderate negative linear correlation between the $\mathrm{IC}_{50}$ values on DPPH $(1 \mathrm{~A})$ (the lower the $\mathrm{IC}_{50}$ value, the higher antioxidant activity observed) and the total phenolic contents ( $\mathrm{r}=-0.53, p=0.004)$, indicating that the antioxidant activity of these extracts is directly related to their phenolic content.

Table 5: Evaluation of the in vitro correlation between the in vitro antioxidant activity and the concentrations of coumarins, total phenolics and flavonoid classes

\begin{tabular}{|c|c|c|c|c|}
\hline \multirow[t]{2}{*}{ Secondary metabolite } & \multicolumn{4}{|c|}{ Correlation coefficient } \\
\hline & DPPH centralize & $p$-value & FRAP & $p$-value \\
\hline aTotal phenols & -0.53 & $0.004^{* *}$ & -0.56 & 0.112 \\
\hline aFlavonoids & -0.21 & 0.300 & 0.29 & 0.435 \\
\hline bCoumarins & -0.17 & 0.392 & 0.25 & 0.516 \\
\hline
\end{tabular}

${ }^{a}$ Comparison through Pearson's correlation coeficient. ${ }^{b}$ Comparison by Spearman's correlation coefficient 

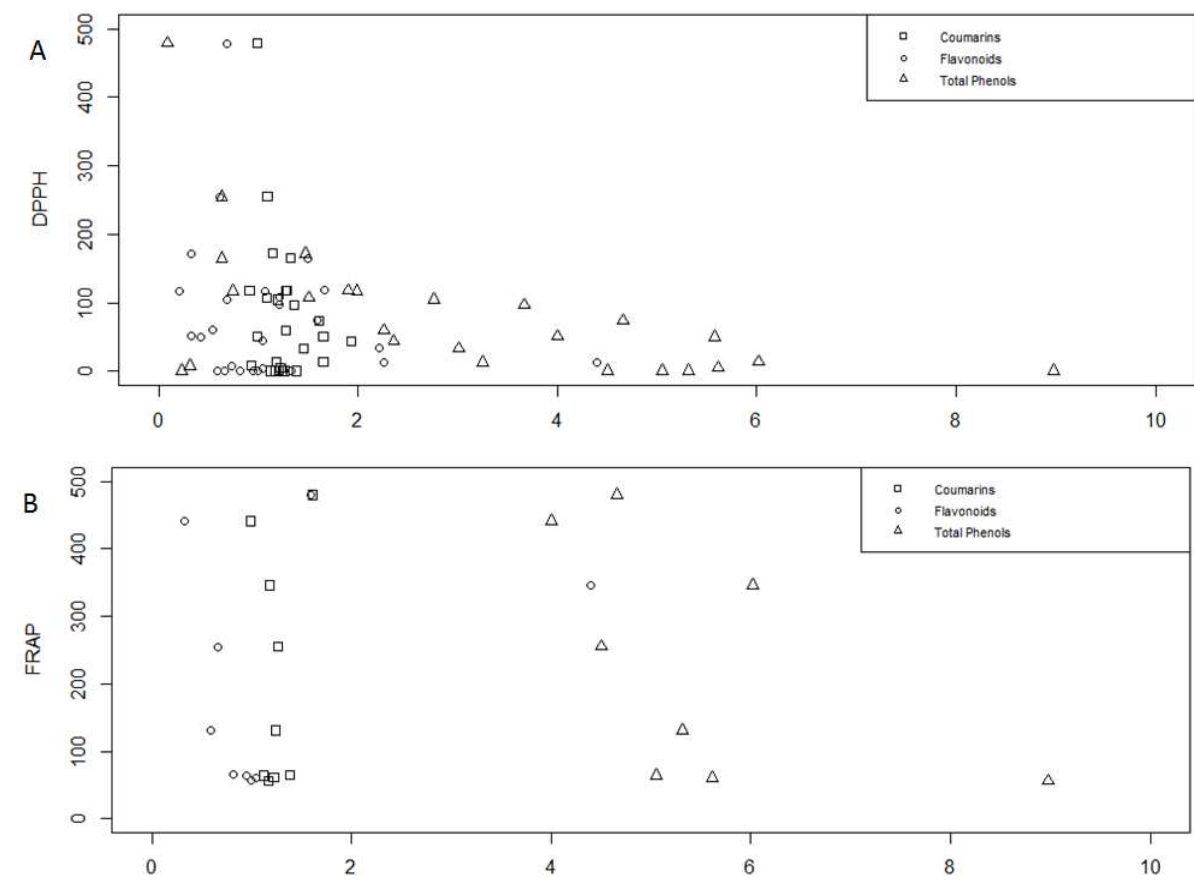

Fig. 1: Scatter graph showing the results of correlation between the antioxidant activity, 2,2-diphenyl-1-picrylhydrazyl (DPPH, A) radical, ferric reducing antioxidant power (FRAP, B) and the concentrations of coumarins, total phenolics and flavonoid classes

These results are in accordance with the findings of Sousa et al., Spagolla et al. and Oliveira et al. and diverge from the findings of Carpes et al. and Rodríguez-Rojo et al. [69-73]. The reasons for these divergences are many and may be due to differences in chemical composition or in contents of different metabolic classes or other unknown factors related to the methodologies or nature of the extracts.

Moreover, literature findings are controversial as to the existence of an association between antioxidant activity and flavonoid or coumarin content in plant extracts [74-77].

Plants rich in flavonoids and phenolic are a good source of natural antioxidant and antibacterial activities. Qualitative and quantitative analysis of major individual phenolic in these extracts explains the relationships between total antioxidant capacity and total phenolic contents in these plants. The presence of phenolic content in plants strongly reveals the antioxidant activity $[78,79]$.

\section{CONCLUSION}

Based on our results, we were able to identified promising medicinal plants from Legal Amazon, as readily available novel candidates for herbal medicines with moderated to elevated broad-spectrum antibacterial activities, such as P. glabra, $H$. coronarium and $H$. microphyla and $C$. nodosa with low spectrum, but the latter showed elevated activity against pathogenic bacteria of great clinic relevance. As potential antifungals, the activities displayed by $B$. excelsa, A. cymbifera, D. polyacanthos and $C$. rubra for being active against Aspergillus and $C$. odorata, for being the only extract active against dermatophytes, are noteworthy.

The extracts acted through bacteriostatic mechanisms. Concerning antioxidant activity, we highlight B. excelsa, C. rubra and C. odorata, for being active in both DPPH and FRAP assays. The antioxidant activities of the extracts are associated to the total phenolic contents. Further chemical isolation of candidate molecules and more detailed work is warranted for the elucidation of the activity and mechanism of action of selected extracts for possible pharmacological and industrial applications. Our results justified the specific use of some of the investigated plants in the Brazilian ethnomedicine.

These findings support that a number of investigated plants could be a valuable source of new antioxidant and antimicrobial compounds that can potentially deliver novel mechanisms of actions. Further studies are warranted to follow our observations.

\section{ACKNOWLEDGMENT}

We are grateful to CNPq/Bionorte (no. 205978/2011) for granting fellowship to the first author, Fundação de Amparo à Pesquisa do Estado de Mato Grosso (FAPEMAT/Bionorte, process no. 551737/ 2010-7) and CAPES-Pró-Amazônia (process no. 100234/2013) for financial assistance in the execution of the project. We are also grateful to PNPD/CAPES and PROPEq/UFMT for providing research fellowships and Instituto Nacional de Ciência e Tecnologia em Áreas Úmidas (INAU)/CNPq/MCTI for the award of a research fellowship (DTI 1A) to Dr. Sikiru Olaitan Balogun (process No. 380909/2015-4).

\section{AUTHORS' CONTRIBUTION}

Larissa Irene da Silva: conceived, executed the assays and participated in the writing of the manuscript

Fabio Miyajima: participated as co-supervisor in the study

Ivana Maria Povoa Violante: Participated in the performance of the antioxidant studies

Isanete Geraldini Costa Bieski: Participated in the collection and identification of plants studied

Sikiru Olaitan Balogun: Participated in the writing of the manuscript

Karuppusamy Arunachalam: Participated in the writing of the manuscript

Domingos Tabajara De Oliveira Martins: Conceived and supervised the studies and participated in the writing and correction of the manuscript

\section{CONFLICT OF INTERESTS}

The authors report no conflicts of interest regarding this manuscript

\section{REFERENCES}

1. Bieski IGC, Leonti M, Arnason JT, Ferrier J, Rapinski M, Violante $\mathrm{IM}$, et al. Ethnobotanical study of medicinal plants by the population of Juruena Valley Region, Legal Amazon, Mato Grosso, Brazil. J Ethnopharmacol 2015;173:383-23. 
2. Lewinsohn TM, Prado PI. Biodiversidade brasileira: síntese do estado atual do conhecimento. Brasil: Editora Contexto; 2002.

3. Instituto Brasileiro de Geografia e Estatística (IBGE). Os indígenas no censo demográfico 2010:primeiras considerações com base no quesito cor ou raça. Rio de Janeiro, BR; 2012.

4. Instituto Brasileiro de Geografia and Estatística (IBGE). Perfil dos estados brasileiros: 2012. Rio de Janeiro, BR; 2013.

5. O’Neill J. The Review on Antimicrobial Resistance. Tackling a global health crisis: initial steps; 2015.

6. Harvey AL, Edrada-Ebel RA, Quinn RJ. The re-emergence of natural products for drug discovery in the genomics era. Nat Rev Drug Discovery 2015;14:111-29.

7. Vatansever F, de Melo WCMA, Avci P, Vecchio D, Sadasivam M, Gupta A, et al. Antimicrobial strategies centred around reactive oxygen species--bactericidal antibiotics, photodynamic therapy, and beyond. FEMS Microbiol Rev 2013;6:955-89.

8. Silva DGH, Belini Junior E, de Almeida EA Bonini-Domingos CR. Oxidative stress in sickle cell disease: an overview of erythrocyte redox metabolism and current antioxidant therapeutic strategies. Free Radical Biol Med 2013;65:1101-9.

9. Nolte 0 . Antimicrobial resistance in the 21st century: a multifaceted challenge. Protein Pept Lett 2014;21:330-5.

10. Coppo E, Marchese A. Antibacterial activity of polyphenols. Curr Pharm Biotechnol 2014;15:380-90.

11. Kim SJ, Cho AR, Han J. Antioxidant and antimicrobial activities of leafy green vegetable extracts and their applications to meat product preservation. Food Control 2013;29:112-20.

12. Niki E. Assessment of antioxidant capacity in vitro and in vivo. Free Radical Biol Med 2010;49:503-15.

13. Bieski IGC, Rios-Santos F, de Oliveira RM, Espinosa MM, Macedo M, Albuquerque UP, et al. Ethnopharmacology of medicinal plants of the Pantanal region (Mato Grosso, Brazil). J Evidence-Based Complementary Altern Med 2012;12:1-36.

14. Mors WB, Rizzini CT, Pereira N. Medicinal Plants of Brazil. Ed. Reference Publications, Algonac, Michigan (USA); 2000. p. 501.

15. National Committee for Clinical Laboratory Standards (CLSI). Reference Method for Broth Dilution Antifungal Susceptibility Testing of Yeasts. Document; 2008. p. M27-A3.

16. National Committee for Clinical Laboratory Standards (CLSI). Methods for dilution antimicrobial susceptibility test for bacteria that grow aerobically. Document; 2015. p. M07-A10.

17. Holetz FB, Pessini GL, Sanches NR. Screening of some plants used in the Brazilian folk medicine for the treatment of infectious diseases. Mem Inst Oswaldo Cruz 2002;7:1027-31.

18. Mbah JA, Ngemenya NM, Abawah AL. The bioassay-guided discovery of antibacterial agents: in vitro screening of Pepermia vulcanica, Peperomia fernandopoioana and Sclerias triatinux. Ann Clin Microbiol Antimicrob 2012;11:2-10.

19. Karki R, Sahi N, Jeon ER, Park YS, Kim DW. Chungtaejeon, a korean fermented tea, scavenges oxidation and inhibits cytokine-induced proliferation and migration of human aortic smooth muscle cells. Plant Foods Human Nutr 2011;66:27-33.

20. Moyo M, Ndhlala AR, Finnie JF, Staden JV. Phenolic composition, antioxidant and acetylcholinesterase inhibitory activities of Sclerocaryabirrea and Harpephyllum caffrum (Anacardiaceae) extracts. Food Chem 2010;1:69-76.

21. Sreejayan MNA, Rao. Nitric oxide scavenging by curcuminoids. J Pharm Pharmacol 1997;1:105-1-7.

22. Amorim ELC, Nascimento JE, Monteiro JM, Sobrinho TJSP, Araújo T, Albuquerque UP. A simple and accurate procedure for the determination of tannin and flavonoid levels and some applications in ethnobotany and ethnopharmacology. Func Ecosyst Commun 2008;2:88-94.

23. Brasil. Farmacopeia Brasileira, volume 2/Agência Nacional de Vigilância Sanitária. 5th Edition. Brasília: ANVISA; 2010. p. 546. Available from: http://www.anvisa.gov.br/hotsite/cd_farmacopeia/pdf/volum e1.pdf. Last accessed on 17 Aug 2015]

24. Tomsone L, Kruma Z, Galoburda R. Comparison of different solvents and extraction methods for isolation of phenolic compounds from horseradish roots (Armoracia rusticana) World Acad Sci Eng Technol 2012;64:903-8.

25. Cechinel Filho V. Chemical composition and biological potential of plants from the genus Bauhinia. Phytother Res 2009;23:1347-54.
26. Giske CG, Monnet DL, Cars O, Carmeli Y. Clinical and economic impact of common multidrug-resistant gram-negative bacilli. Antimicrob Agents Chemother 2008;52:813-21.

27. Joy B, Rajan A, Abraham E. Antimicrobial activity and chemical composition of essential oil from Hedychium coronarium. Phytother Res 2007;21:439-43.

28. Joshi S, Chanotiva CS, Agarwal G, Prakash O, Pant AK, Mathela CS. Terpenoid compositions, and antioxidant and antimicrobial properties of the rhizome essential oils of different Hedychium species. Chem Biodiversity 2008;2:299-309.

29. Suksathan R, Sookkhee S, Anuntalabhochai S, Chansakaow S. Chemical composition and antibacterial activity of rhizome oils from five Hedychium species. Nat Prod Commun 2013;4:519-22.

30. Ho JC. Antimicrobial, mosquito larvicidal and antioxidant properties of the leaf and rhizome of Hedychium coronarium. J Chin Chem Soc 2011;58:563-7.

31. Reuk-ngam NR, Chimnoi N, Khunnawutmanotham N, Techasakul S. Antimicrobial activity of coronarin $d$ and its synergistic potential with antibiotics. Biomed Res Int 2014;1:1-8.

32. Gobbo-neto L, Lopes NP. Plantas medicinais: fatores de influência no conteúdo de metabólitos secundários. Quím Nova 2007;30:374-81.

33. Llorach R, Martínez-Sánchez A, Tomás-Barberán FA, Gil MI Ferreres F. Characterisation of polyphenols and antioxidant properties of five lettuce varieties and escarole. Food Chem 2008;108:1028-38.

34. Maji S, Dandapat P, Ojha D, Maity C, Halder SK, Mohapatra Das PK. In vitro antimicrobial potentialities of different solvent extracts of ethnomedicinal plants against clinically isolated human pathogens. J Phytopathol 2010;4:57-64.

35. Souza LBG, Figueiredo BB. Prevalência de infecções nosocomiais provocadas por Staphylococcus aureus resistente à meticilina (MRSA), no hospital universitário regional de maringa. Rev Bras Anal Clin 2008;40:31-4.

36. Santos RFEP, Silva ISMS, Costa LR. Study of antimicrobial potential and cytotoxic of Cordia nodosa species. BMC Proc 2014;8:69-70.

37. Fiedler T, Koeller T, Kreikemeyer B. Streptococcus pyogenes biofilms-formation, biology, and clinical relevance. Front Cell Infect Microbiol 2015;5:1-15.

38. Murray P, Rosenthal KS, Pfaller MA. Medical microbiology. 7nd edition. Elsevier Health Sciences; 2012.

39. Lima Neto GA, Batista AL, Chang MR. Antibacterial activity and free radical-scavenging properties of medicinal plants from the cerrado of brazil. Brasil: IV Simpósio iberoamericano de plantas medicinais; 2009.

40. Liu W, Liu Y, Zhang X. In vitro bactericidal activity of jinghua weikang capsule and its individual herb Chenopodium ambrosioides L. against antibiotic-resistant Helicobacter pylori. Chin J Integr Med 2013;19:54-7.

41. Maduka HCC, Okpogba AN, Ugwu CE, Dike CC, Ogueche PN, Onwuzurike DT, et al. Phytochemical, antioxidant and microbial inhibitory effects of Spondias mombin leaf and stem bark extracts. J Pharm Biol Sci 2014;9:14-7.

42. Martins M, Klusczcovski AM, Scussel VM. In vitro activity of the Brazil nut (Bertholletia excelsa H. B. K.) oil in aflatoxigenic strains of Aspergillus parasiticus. Eur Food Res Technol 2014;239:687-93.

43. Raven PH, Evert RF, Curtis H. Biologia Vegetal. $7^{\text {nd }}$. Guanabara Koogan; 2007.

44. Kuse E, Chetchotisakd P, Cunha CA, Ruhnke M, Barrios C, Raghunadharao D, et al. Micafungin versus liposomal amphotericin B for candidaemia and invasive candidosis: a phase III randomised double-blind trial. Lancet 2007;9572:1519-27.

45. Park BJ, Wannemuehler KA, Marston BJ, Govender N, Pappas PG, Chiller TM. Estimation of the current global burden of cryptococcal meningitis among persons living with HIV/AIDS. AIDS 2009;4:525-30.

46. Andrade DFR. Microbiota fúngica no ar em unidades de terapia intensiva and centros cirúrgicos. Rev Pre Infece Saúde 2015;1:74-81

47. Tempone AG, Sartorelli P, Teixeira D, Prado FO, Calixto IARL, Lorenzi $\mathrm{H}$, et al. Brazilian flora extracts as source of novel 
antileishmanial and antifungal compounds. Mem Inst Oswaldo Cruz 2008;103:443-9.

48. Kousha M, Tadi R, Soubani AO. Pulmonary aspergillosis: a clinical review. Eur Respir Ver 2011;20:156-74.

49. Shah A, Panjabi C. Allergic aspergillosis of the respiratory tract. Eur Respir Rec 2014;23:8-29.

50. Idu M, Oshomoh EO, Ovuakporie-Uvo PO. Phytochemistry and antimicrobial properties of Chlorophora excelsa, Cedrela odorata and Tectona grandis Topcls. J Herb Med 2013;2:248-53.

51. Ganeshkumar P, Hemamalini M, Lakshmanan A, Madhavan R, Raam Mohan S. Epidemiological and clinical pattern of dermatomycoses in rural India. Indian I Med Microbiol 2015;33:134-6.

52. Ghannoum MA, John RP. Antifungal Therapy. Publisher Taylor and Francis; 2009.

53. Kintzios S, Papageorgiou K, Yiakoumettis I, Baricevic D, Kusar A. Evaluation of the antioxidants activities of four slovene medicinal plant species by traditional and novel biosensory assays. J Pharm Biomed Anal 2010;53:773-6.

54. Engler MB, Engler MM. The emerging role of flavonoid rich cocoa and chocolate in cardiovascular health and disease. Nutr Rev 2006;64:109-18.

55. Locatelli M, Gindro R, Travaglia F, Coïsson J, Rinaldi M, Arlorio M. Study of the DPPH-scavenging activity: development of a free software for the correct interpretation of data. Food Chem 2009;114:889-97.

56. Serafini M, Bugianesi R, Maiani G, Valtuena S, Santis S, Crozier A. Plasma antioxidants from chocolate. Nature 2003;424:1013.

57. John JA, Shahidi F. Phenolic compounds and antioxidant activity of Brazil nut (Bertholletia excelsa). J Funct Foods 2010;2:196-209.

58. Buratto AP, Carpes ST, Vecchia PD, Loss EMS, Appelt P. Determinação da atividade antioxidante e antimicrobiana em Castanha-do-Pará (Bertholletia excelsa). Rev Brasi Pesq Alim 2011;2:60-5.

59. Lima EF, Sousa-Filho PT, Bastida J, Schmeda-Hirschmann G. Saponins from Cariniana rubra (Lecythidaceae). Bol Soc Chil Quim 2002;47:441-7.

60. Lima DCA. Estudo comparativo da atividade antioxidant de plantas medicinais da Caatinga utilizadas como antinflamatórias, Master's thesis, Universidade Federal de Pernambuco; 2011.

61. Rashed K. Hepatoprotective effect from Cedrela odorata and phytochemical profile. J Pharm Cosmet Sci 2013;3:45-52.

62. Giordani MA, Collicchio TCM, Ascêncio SD, Martins DT, Balogun SO, Bieski IG, et al. Hydroethanolic extract of the inner stem bark of Cedrela odorata has low toxicity and reduces hyperglycemia induced by an overload of sucrose and glucose. J Ethnopharmacol 2015;162:352-61.

63. Akinmoladun AC, Khan MF, Sarkar J, Farombi EO, Maurya R. Distinct radical scavenging and antiproliferative properties of Spondias mombin and antioxidant activity-guided isolation of quercetin-3-0- $\beta$-Dglucopyranoside and undec-1-ene. Afr J Pharm Pharmacol 2015;17:506-13.

64. Akinmoladun AC, Obuotor EM, Farombi EO. Evaluation of antioxidant and free radical scavenging capacities of some nigerian indigenous medicinal plants. J Med Food 2010;13:444-51.

65. Igwe CU, Onyeze GOC, Onwuliri VA, Osuagwu CG, Ojiako AO. Evaluation of the chemical compositions of the leaf of spondias mombin linn from nigeria. Aust J Basic Appl Sci 2010;5:706-10.
66. Fernandes RS. Frutas, sementes and amêndoas silvestres alimentícias na comunidade indígena tunuí cachoeira, Ph. D thesis, Universidade Federal de Lavras; 2012.

67. Barros L, Pereira E, Calhelha RC, Dueñas M, Carvalho AM, Santos-Buelga C, et al. Bioactivity and chemical characterization in hydrophilic and lipophilic compounds of Chenopodium ambrosioides L. J Funct Foods 2013;5:1732-40.

68. Sowndhararajan K, Kang SC. Free radical scavenging activity from different extracts of leaves of Bauhinia vahlii wight and Arn. Saudi J Biol Sci 2013:4:319-25.

69. Sousa CMM, Silva HRS, Vieira-Jr GM. Fenóis totais and atividade antioxidant de cinco plantas medicinais. Quim Nova 2007;30:351-5.

70. Spagolla LC, Santos MM, Aguiar LML. Extração alcoólica de fenólicos and flavonóides totais de mirtilo "Rabbiteye" (Vaccinium ashei) e sua atividade antioxidante. Rev Ciênc Farm Básica Appl 2009;2:59-64.

71. Oliveira GLS, Júnior ALG, Oliveira FRAM. Avaliação da capacidade antioxidant in vitro and in vivo do extrato etanólico da Copernicia prunifera (Mill.) HE Moore. Rev Cienc Farm Basica Appl 2014;2:293-300.

72. Carpes ST, Prado A, Moreno IAM, Mourao GB, Alencar SM, Masson ML. Avaliacao do potencial antioxidant do polen apícola produzido na regiao sul do Brasil. Quim Nova 2008;31:1660-4.

73. Rodriguez-Rojo S, Visentin A, Maestri D, MJ Cocero. Assisted extraction of rosemary antioxidants with green solvents. J Food Eng 2012;109:98-103.

74. Ghasemi K, Ghasemia Y, Ebrahimzadeh MA. Antioxidant activity, phenol and flavonoid contents of 13 citrus species peels and tissues. Pak J Pharm Sci 2009;22:277-81.

75. Alothman M, Bhat R, Karim AA. Antioxidant capacity and phenolic content of selected tropical fruits from Malaysia, extracted with different solvents. Food Chem 2009;115:7858.

76. Infante J, Selani MM, Toledo NMV, Silveira-Diniz MF, Alencar SM, Spoto MHF. Atividade antioxidant de resíduos. Alim Nutr Braz J Food Nutr 2013;24:87-91.

77. Araújo TAS, Sobrinho TJSP, Aguiar JS, Silva ACO, Brito FU, Silva G, et al. Phytochemical, antioxidant and cytotoxic analysis of Brazilian cerrado plants: preliminary evidence of their antitumor activity. J Med Plants Res 2015;9:310-9.

78. Manigandan M, Kolanjinathan K. Qualitative phytochemical screening and antioxidant activity of Elytraria acaulis lindau (acanthaceae). Asian J Pharm Clin Res 2016;9:1-4.

79. Slimani Alaa, Moussaoui Abdellah, Laazouni Hamadi. Phytochemical screening, contribution to the study of the antifungal effect of flavonoids from different parts of Ziziphus lotus of south-west Algeria. Asian J Pharm Clin Res 2017;10:13-6.

\section{How to cite this article}

- Larissa Irene Da Silva, Arunachalam Karuppusamy, Fabio Miyajima, Ivana Maria Povoa Violante, Isanete Geraldini Costa Bieski, Sikiru Olaitan Balogun, Domingos Tabajara De Oliveira Martins. Antimicrobial and antioxidant activities of selected plants used by populations from juruena valley, legal amazon, brazil. Int J Pharm Pharm Sci 2017;9(5):179-191. 